\title{
The stress peak at the borehole of point-fitted IGU with undercut anchors
}

\author{
Mike Tibolt* and Christoph Odenbreit \\ ArcelorMittal Chair of Steel and Façade Engineering, University of Luxembourg \\ Submitted 7 May 2014 \\ Revised 26 September 2014 \\ Accepted 18 October 2014
}

\begin{abstract}
The highest transparency in glass facades is obtained with point fitted glass units. Point fitted insulating glass units minimize thermal bridging and lead to glass facades with better energy efficiency. Though, insufficient knowledge is present to offer a design method for point fittings in insulating glass. Therefore research has been carried out to extend the existing SLG-design-method (Linear superposition of local and global stress components) of Beyer for point fitted single and laminated glass to insulation glass units. This paper presents the first results of this research campaign. Load bearing tests on point fittings in single glazing have been conducted. A finite element model of the point fitting is calibrated by strain comparison. A test campaign for the deviation of a material law for silicone, used as secondary sealant in the edge seal system, is presented. The verified FE-model is implemented in a selected insulation glass unit, and the influence of the edge distance of the point fitting, as well as the edge bond stiffness and geometry on the stress peak at the borehole is investigated. In addition, the size of the so called 'local area' is adjusted for insulation glass units.
\end{abstract}

Keywords: Energy efficiency, insulation glass, climate loads, stress peak, finite element method

\section{Introduction}

\subsection{Motivation}

During the last decades, structural glass elements have become a main construction element in modern architecture. The main advantage of glass compared to other construction materials like steel or concrete is its transparency. It allows the design of highly transparent facades with a large gain of natural illumination.

The strategy 'EU2020' formulated by the European Union in the year 2010 will have a strong impact on the design of glass facades. The strategy foresees inter alia a reduction of the energy consumption and greenhouse gas emission of $20 \%$ until the year 2020. Since the 160 million buildings in the European Union represent more than $40 \%$ of the European primary energy consumption (heating/cooling and lighting of buildings) and produce about 35\% of all greenhouse emissions ('COM 860', 2007), architecture and the building industries definitively bear an enormous potential to achieve the 'EU2020' climate protection aims. Consequently high demands on the thermal insulation performance of glass facades are made (Wurm, 2007). In Germany, a reference value for the heat transfer coefficient of $\mathrm{U}_{\mathrm{g}}=1.1 \mathrm{~W} / \mathrm{m}^{2} \mathrm{~K}$ (EnEV 2009, 2009) for glass facades is indicated. Only double or triple insulating glass units comply with these limits.

\footnotetext{
${ }^{*}$ Corresponding author: Mike Tibolt, ArcelorMittal Chair of Steel and Façade Engineering, University of Luxembourg. E-mail: mike.tibolt@uni.lu.
} 
Point fitted insulation glass units can be interpreted as the architectural intention to combine the thermal performance of insulation glass units with the high transparency of point fitting connections.

A comparison between the different point fitting types has revealed the undercut anchors to be the most suitable connection type for insulation glass (Tibolt, 2015). Undercut anchors are exclusively drilled in the inner pane and do not penetrate the cavity of the insulation glass unit. Thus, the cavity is not disturbed by openings for the steel bolt of the point fitting and the risk of gas leakage is avoided. Additionally, the steel bolt is not in contact with the external surface of the unit and the thermal bridge due to the connection is marginal. Finally the outer glass pane stays totally even and free of any cover bars or clamping disks and consequently the transparency of the facade is increased.

\subsection{Methodology}

Point fitted insulation glass with undercut anchors are the most promising solution for highly transparent and energy efficient glass facades. However, insufficient knowledge is present to offer a corresponding design concept.

In this paper, a design approach for point fitted insulating glass with the undercut Fischer FZP-G-Z is proposed. It is based on the load bearing mechanism of undercut point fitted insulation glass and provides the verification steps for the different components (Section 4.2).

The challenge in the design of point fitted glazing consists in the determination of the stress peak at the borehole. For point fitted single glazing, several concepts for the determination of the stress peak have been developed (Brendler \& Schneider, 2004; Kasper, 2006; Siebert, 2006; and the 'SLG-method', Beyer, 2007).

The different methods were analysed with regards to a possible extension to point fitted insulation glass and the SLG-method has been revealed to be the most suitable one (Section 3.4). Compared to single glazing, the edge seal system of the insulation glass units additionally influences the stress peak at the borehole. In consequence, the extension of the method requires the adaptation of its factors.

Load bearing tests on the Fischer FZP-G-Z in single glazing have been conducted and an FE-model of the point fitting has been calibrated by strain comparison. The calibrated model was implemented in an insulation glass unit and a parametric study concerning the influence of the edge seal stiffness and geometry on the stress peak at the borehole has been executed. For this purpose, a silicone material law for the secondary sealant has been derived (Dias, 2013).

The results of the parametric study finally allowed the adaption of the factors of the SLG-method to insulation glass.

The paper mainly focuses on the results of the parametric study for a given insulation glass geometry and the adaption of the 'local area'.

\section{The point fitting Fischer FZP-G-Z}

The Fischer FZP-G-Z is an undercut point fitting system marketed by the Fischer-company in Germany. It has been primarily developed for the use in single and laminated glazing (Fig. 1).

In a first step, a cylindrical hole is drilled in the glass pane. Secondly, the cutter head is tilled and the undercut is realized. Subsequently the glass panes are tempered and the point fitting is mounted torque controlled. The expending sleeve opens and finally anchors the point fitting in the glass. 


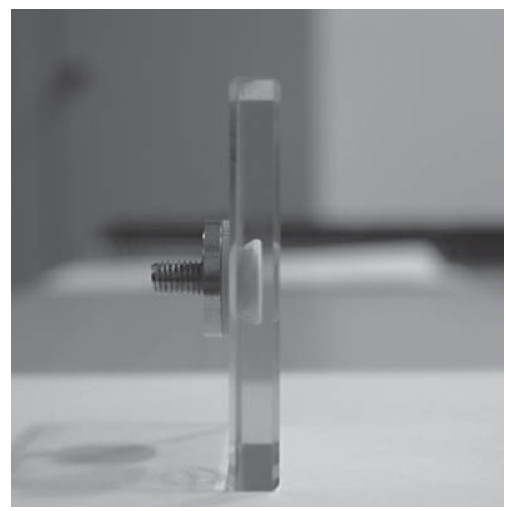

Fig. 1. The Fischer FZP-G-Z.

The main advantage of the Fischer FZP-G-Z consists in the undercut borehole. Compared to the commonly used button and countersunk point fittings, the Fischer FZP-G-Z does not penetrate the glass pane in its entire extent. The outer surface is even and easy to clean. In addition, the point fitting is small in size and the transparency of the glass pane is only marginally reduced. In Germany, a general technical approval for the Fischer FZP-G-Z exists $(Z-70.2-122,2007)$ for single and laminated glazing.

\section{Design of point fitted single glazing}

\subsection{Method according to Brendler}

Brendler (2004) has developed a design methodology based on tests and numerical analysis with the load-deformation behaviour of the point fittings as governing parameter.

For the verification according to Brendler, small-scale static and dynamic tests are conducted on the point fittings at different temperatures, and their load-deformation curves are recorded. The point fittings are applied into steel plates and subjected to compression, tension and shear forces to determine their longitudinal and lateral stiffness values (Fig. 2).
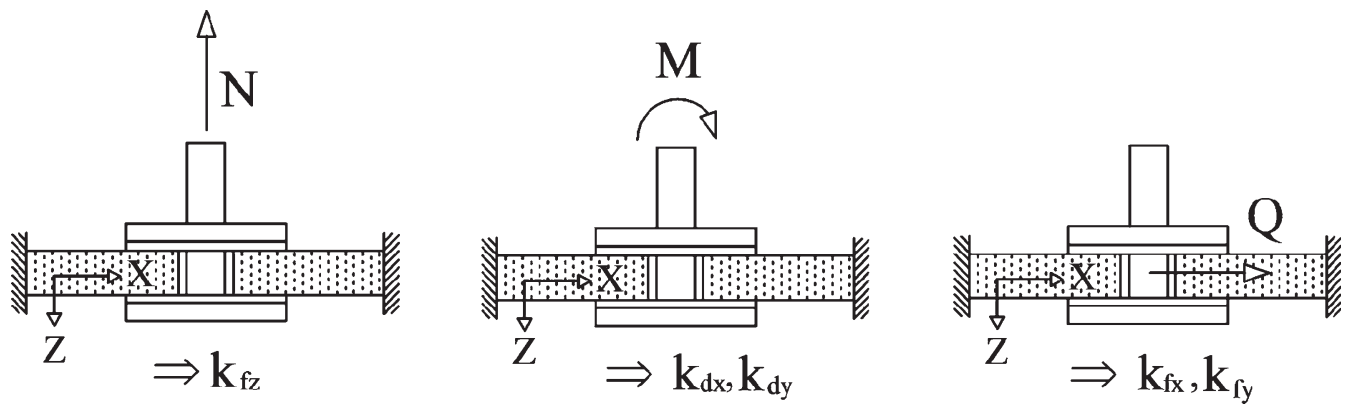

Fig. 2. Test configuration and point fitting stiffness (Brendler \& Schneider, 2004). 
The longitudinal stiffness of the point fitting consists in the flexibility of the interlayers and an eventual hinge. The lateral stiffness is composed of the flexibility of the bush or the filling material and the rotation of the fitting head due to the elastic deformation of the interlayers (Brendler \& Schneider, 2004). The limit stiffness values are implemented in the general technical approval of the corresponding point fitting. A numerical model respecting these limits is considered to correctly simulate the stress peak at the borehole.

For design, in a first step, the designer verifies the head stiffness (longitudinal stiffness) of the point fitting. The point fitting is modelled in a rigid plate and subjected to tension and compression. The Young's modulus of the interlayer is varied until the numerical stiffness of the point fitting lies within the stiffness range given in the data sheets. In a second step the stiffness of an eventual longitudinal joint of the point fitting is verified. Therefore the joint's softness is modelled by a spring. In a third step, the transverse stiffness of the point fitting is verified in the same way as its head and joint stiffness. Finally reference geometry of a glass pane subjected to a surface load is modelled for which the reaction forces, stresses and deflection are provided in the data sheets. For this geometry, the FE-model from the first three steps is to be used. By comparison of the own FE results to the data sheet values for the support reactions, stresses and deformation, the own model is validated. The design of the point-fitting is performed by adoption of this model to the geometry to be designed and subsequent checking of the results against the design values.

The method according to Brendler has been implemented in the approvals of several point fitting systems, e.g. Z-70.2-99 (2004).

\subsection{Method according to Kasper}

Kasper (2006) has developed a design methodology based on tests and numerical analysis.

As a first step to determine the input parameters for the methodology, small-scale tests on glass plates with a centric point fitting are conducted. The test set-up is freely pivotable to realize variable load introduction angles $\left(0^{\circ}, 22.5^{\circ}, 45^{\circ}, 90^{\circ}\right)$ and to take into account the different load cases in the point fitting. The strains on the glass surface are measured during the test along predefined paths (Fig. 3).

A detailed FE-model of the point fitting is developed and calibrated by comparing the numerically determined strains with the measured strains. Finally, the strains and maximum tensile stresses along the paths are determined with the calibrated FE-model and provided in data sheets for the corresponding point fitting.

For the design of the connection, a numerical model of the point fitting is implemented in an adequate FE-program. The model is calibrated by changing the Young's modulus of the interlayers until the calculated strains and stresses comply with the values in the data sheets. The model is subsequently extended to the pane geometry to be verified.

\subsection{Method according to Siebert}

Siebert (2006) has developed a design methodology based on tests and numerical analysis similar to the approach by Kasper.

At first, the parameters for the calibration of the FE-models are determined in small-scale compression tests on glass plates with a centric point fitting. The tests are realized for a symmetrical and eccentric support configuration for the glass plate and conducted once with aluminium as interlayer 

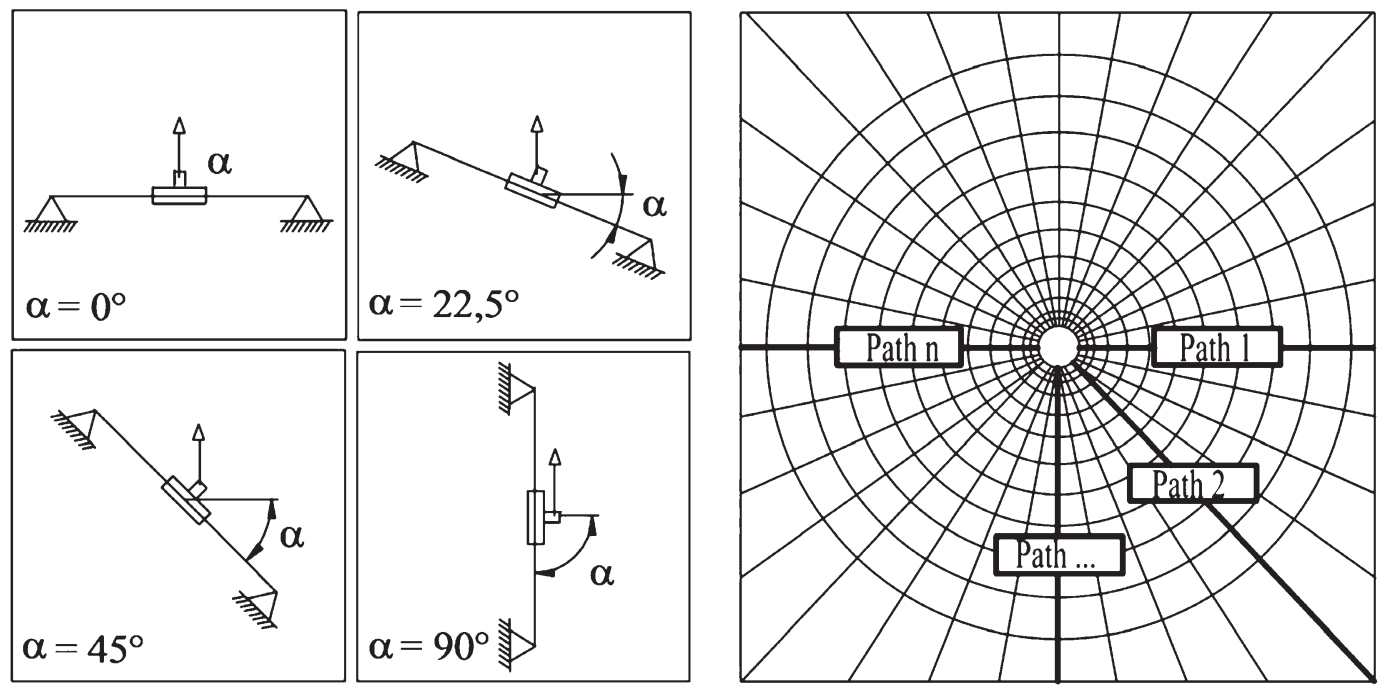

Fig. 3. Test configuration and path definition (Kasper, 2006).

material and once with the real interlayer material of the concerned point fitting. The strains are measured in the test along defined strain paths with rosettes and strain gauges (Fig. 4).

Finally the stresses are calculated out of the measured strains and provided in data sheets for both interlayer properties.

In addition to the approach by Kasper, the finite element model used for design is not only validated for stresses against the specified small-scale tests but also the meshing from the finite element model is verified. Therefore, to develop the FE-model, first a die plate is modelled with finite element methods and subjected to tension. The resulting stress peak occurring at the borehole is compared to analytic results (Young, 1989) to check the quality of the element type. In a second step, the compression tests with a point-fitting and aluminium interlayer is modelled and compared to the measured stresses. Since the aluminium properties are well known, the contact definitions between

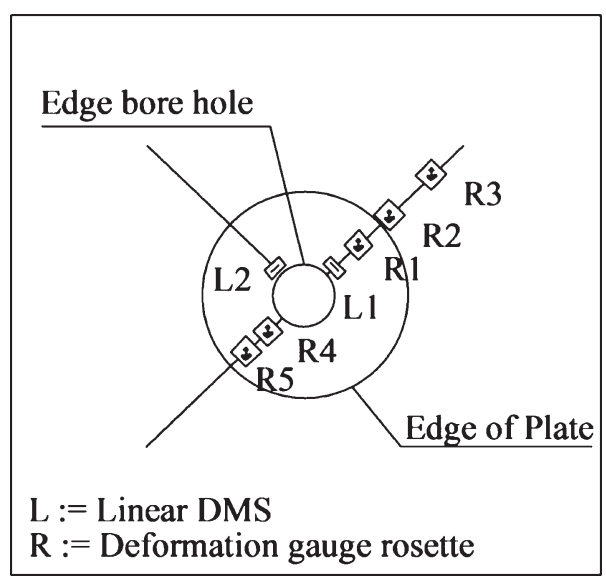

Fig. 4. Position of strain gauges (Siebert, 2006). 
the glass and the point fitting are verified. In a last step, the compression tests are simulated with the real interlayer materials of the point fitting. The numerical model is finally calibrated by changing the Young's modulus of the interlayer in the finite element model until compliance between the measured and numerical stresses is achieved.

The achieved calibrated model is subsequently extended to the geometry of the pane to be designed and the results for stresses and deflection are verified against the resistance and design limits.

\subsection{The SLG-method}

Beyer (2007) developed a design concept for single and laminated glass, the so-called 'SLG-method'. It is based on the separation of the overall global behaviour of the glass plate from the local stress concentration in the borehole area (Fig. 5).

According to the Saint-Venant's Principle, the stress concentration at the borehole decays at a distance of 3 times the borehole diameter. Thus, a circular local area with a radius of at least three times the borehole diameter is defined around the centre of the borehole. The global behaviour of the plate can be covered with a simple 2D-FE-model. In this model, the glass is modelled with shell-elements and the point fittings are represented by springs with corresponding stiffness values. The stiffness of the springs is derived by testing the point fitting in a steel plate. In consequence, there is no need to model neither the borehole nor the point fitting in detail. From this model, the support reactions of the point fittings $(N, Q$ and $M)$ and the maximum global stress component at the rim of the local area are determined. The simple 2D-FE-model is of course not able to determine the stress peak at the borehole since the single node support creates an infinite stress peak at this point. According to the SLG-method, the local stress concentration is separated into components corresponding to the support reactions of the point fitting (Beyer, 2007). The stress components are calculated by multiplication of the support reactions with so called 'stress component factors'. The factors depend on the dimension of the point fitting, the thickness of the plate and the stiffness of the interlayers. They are generated by detailed FE calculation for a reference plate thickness of $10 \mathrm{~mm}$ and tabulated for the corresponding point fitting system (Beyer, 2009). The maximum tensile stress at the borehole is conservatively determined by linear superposition of the local and global stress components (SLG-method). The global stress component is increased by a stress concentration factor $\mathrm{k}$, which considers the stress concentration in a plate with a hole under pure bending. The factor is defined as the quotient of the maximum stress peak at the borehole and the global stress component. It depends on the plate thickness and the position of the borehole. The factor is determined by FEsimulation of a plate with the detailed borehole geometry under pure flexion and it is tabulated for the corresponding point-fitting type (Beyer, 2009).

The verification of a point-fitted single or laminated glass pane according to the SLG-method consists in the verification of the serviceability and ultimate limit states: In the serviceability limit state, the maximal deformation in the mid-span or at the edge of the glass plate is calculated with the simple 2D-FE-model and limited to the corresponding design value, e.g. DIN 18008-3 (2013). In the ultimate limit state, the maximal tensile stress peak at the borehole is determined as described and limited to the ultimate glass strength, e.g. DIN 18008-1 (2010).

The SLG-method has been first implemented in the general technical approval of the Fischer FZPG-Z (Z-70.2-122, 2007). Additionally, DIN 18008-3 (2013) allows the verification of point fitted single glazing with button fittings according to the SLG-method. 


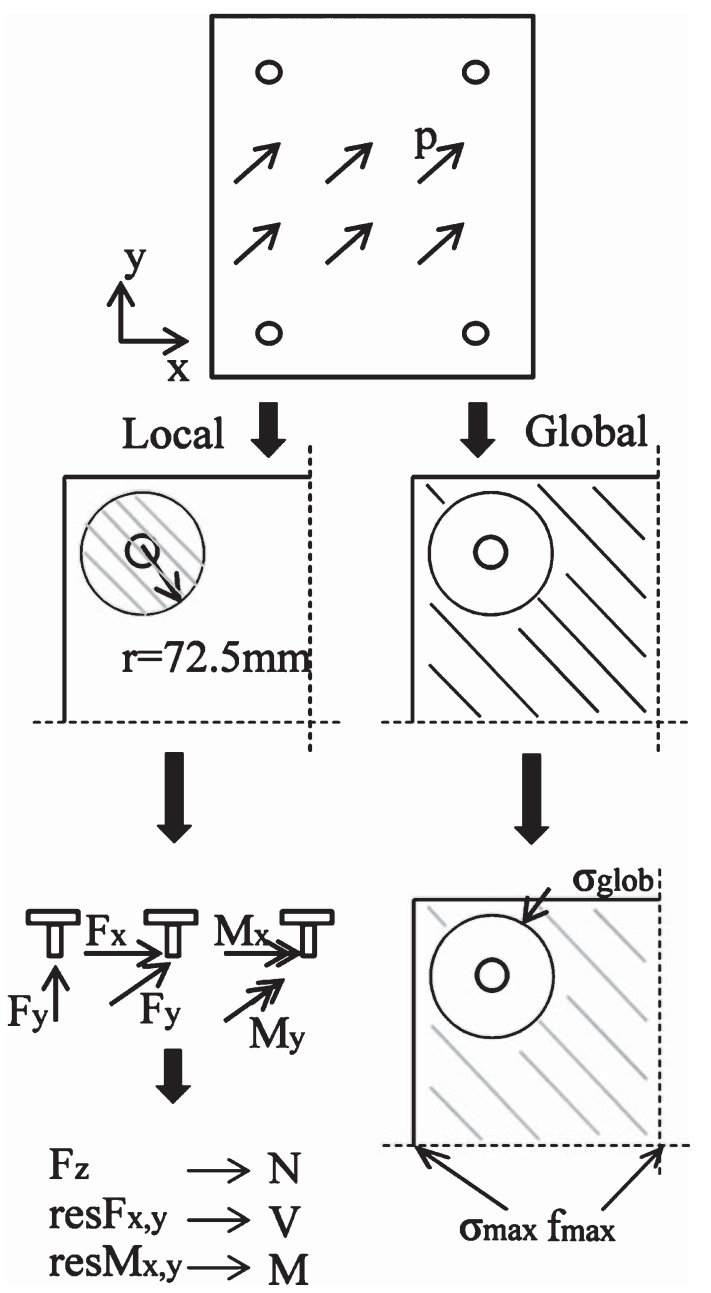

Fig. 5. Principle of the SLG-method.

Compared to the other concepts, the advantage of the SLG-method consists of the easy FEmodelling. A simple 2D-FE-model is sufficient for design and the detailed borehole and point-fitting modelling is unnecessary. Additionally, the SLG-method is based on an engineering model and not on a "trial and error" concept, which is the case for the other methods. In consequence, the SLG-method has been retained for the extension to insulation glass units.

\section{Point fitted insulation glass with undercut anchors}

\subsection{Load bearing mechanism}

In undercut point-fitted insulation glass units, the inner and outer glass panes are coupled via the gas in the cavity and the edge seal system. The loads acting on the outer glass pane are transmitted 


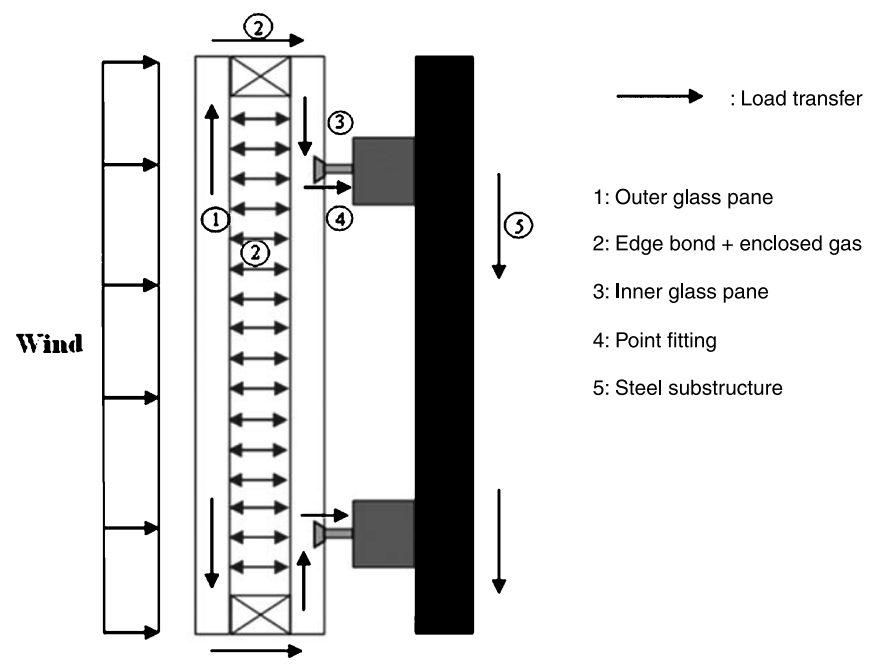

Fig. 6. Load bearing mechanism of undercut point fitted insulation glass.

to the inner pane via the edge seal system, which accordingly assumes a structural role. Finally the loads are transferred from the inner glass pane to the substructure via the point fittings. Figure 6 shows the load bearing mechanism of undercut point fitted insulation glass units.

\subsection{Design approach for undercut point-fitted IGU}

A design approach of undercut anchors in insulation glass units (explicitly the Fischer FZP-G-Z) for vertical glazing (max. 10\% inclination) has been proposed by Hechler, Dias, Odenbreit, Tibolt and Zilian (2012).

The design procedure proceeds in 5 steps (Fig. 7) and accounts for the load bearing mechanism described in section 4.1:

1. In a first step, the inner and outer loads acting on each glass pane are determined. The outer loads (e.g. wind) are determined according to the respective standards (EN 1991-3, 2010; EN 1991-4, 2010). The inner loads are the climate loads due to the encapsulated gas in the glazing cavity. Tibolt, Hechler, and Odenbreit (2014) developed a climate load model for the determination of the climate loads of undercut point fitted insulation glass units. In fact, the method described in DIN 18008-2 Annex $A$ is only valid for linearly supported IGU. For instance, the factor $B_{V}$ has been derived for a glass pane supported on its four edges. Therefore the method cannot be directly applied to point fitted IGUs with undercut ties. The method of Feldmeier has to be adapted to the static system of point fitted IGU with undercut ties. This is done in Tibolt et al. (2014).

2. Secondly, a numerical model of the insulation glass units is implemented in an appropriate FEsoftware. The point fittings are represented by springs with corresponding stiffness values and the glass panes are modelled with 2D-shell elements. The edge bond is represented with 3Dsolid elements, taking into account its detailed geometry and the material laws for the different components (e.g. sealants and spacer). 


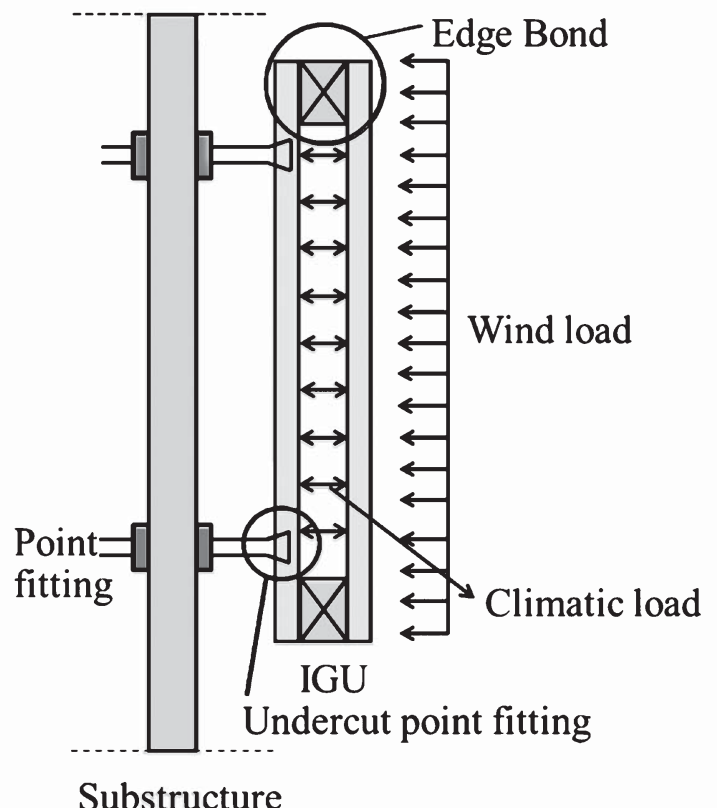

Fig. 7. Loads acting on insulation glass (Hechler et al., 2012).

3. In a third step, the structural edge bond is verified according to ETAG 002 (2012). The minimal covering thickness of the secondary sealant is determined in dependency of the stress state in the silicone and its ultimate design strength (ETAG 002, 2012).

4. Fourthly, the outer glass pane is verified. The maximal tensile stresses and deformations are numerically determined with the simple 2D-FE model and checked against the ultimate glass strength respectively deformations given in DIN 18008-1 (2010).

5. In a last step, the inner pane is verified according to the extended SLG-method (Tibolt, 2015). The stress peak at the borehole is determined and limited to the ultimate glass strength. In parallel, the maximal tensile stresses and deformations in the mid-span or the edges of the glass pane are numerically determined and compared to the ultimate design values in DIN 18008-1 (2010).

\section{ULS testing of the Fischer FZP-G-Z in fully tempered monolithic glass}

\subsection{Objectives}

With the aim to solidify the data given for the Fischer FZP-G-Z in the German general technical approval Z-70.2-122 (2007) and to calibrate and verify an own FE-model of the point fitting, component tests have been conducted.

The ultimate load bearing capacity of the Fischer FZP-G-Z is recorded and strains are measured during the tests to create a data set for the calibration of the numerical model of the point fitting. 


\subsection{Test description}

Similar tests have already been conducted at the 'Institut für Konstruktiven Ingenieurbau (IKI) der Universität für Bodenkultur in Wien' (Beyer, 2007) in conjunction with the establishment of the general technical approval Z-70.2-122 (2007). The test set-up designed at the University of Luxembourg is comparable to the test configuration at the 'IKI' (Schneider, Hof \& Block, 2002).

The test set-up (Fig. 8) allows the load introduction at the Fischer FZP-G-Z under different angles: $0^{\circ}$ (pure tension), $45^{\circ}$, (diagonal pull) and $90^{\circ}$ (shear and bending).

The tested fully tempered monolithic glass panes have the dimensions of $350 \times 350 \mathrm{~mm}$ and a thickness of $10 \mathrm{~mm}$ respectively $12 \mathrm{~mm}$. For testing, the glass samples are positioned on a polyamide (PA6) ring with a diameter of $145 \mathrm{~mm}$ to avoid glass to steel contact. At the same time, the diameter of the ring defines the size of the local area introduced by the SLG-method (Beyer, 2007). The ring is glued to a steel plate welded on U-profiles, which can be positioned at different angles. The load is introduced by draw shackles directly into the point fitting.

It is impossible to subject the FZP-G-Z to pure shear in tests, since a lever arm will be present for load introduction. In the test presented in this paper, the measured lever arm is $16.5 \mathrm{~mm}$ (Fig. 9).

The different test series are listed in Table 1.

For each series, the tests were conducted displacement controlled with a speed of $0.4 \mathrm{~mm} / \mathrm{min}$ at room temperature (circa. $25^{\circ} \mathrm{C}$ ) until failure of the connection (glass breakage).
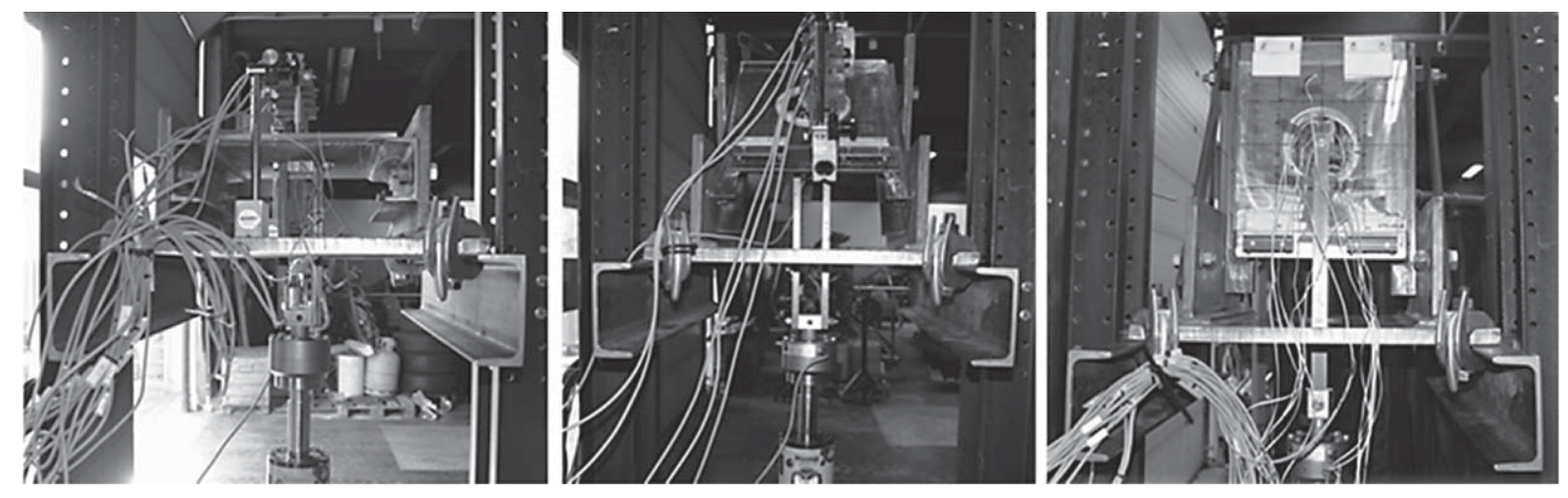

Fig. 8. Small scale test configurations.

Table 1

Test series

\begin{tabular}{lccc}
\hline Test & Parameter & $\mathrm{t}_{\text {pane }}(\mathrm{mm})$ & No.of samples \\
\hline Tension & $\mathrm{N}$ & 10 & 5 \\
\multirow{3}{*}{ Shear } & & 12 & 6 \\
& $\mathrm{Q}$ & 10 & 5 \\
Diagonal Pull & $\mathrm{N}+\mathrm{Q}$ & 12 & 5 \\
& & 10 & 5 \\
& & 12 & 5 \\
\hline
\end{tabular}




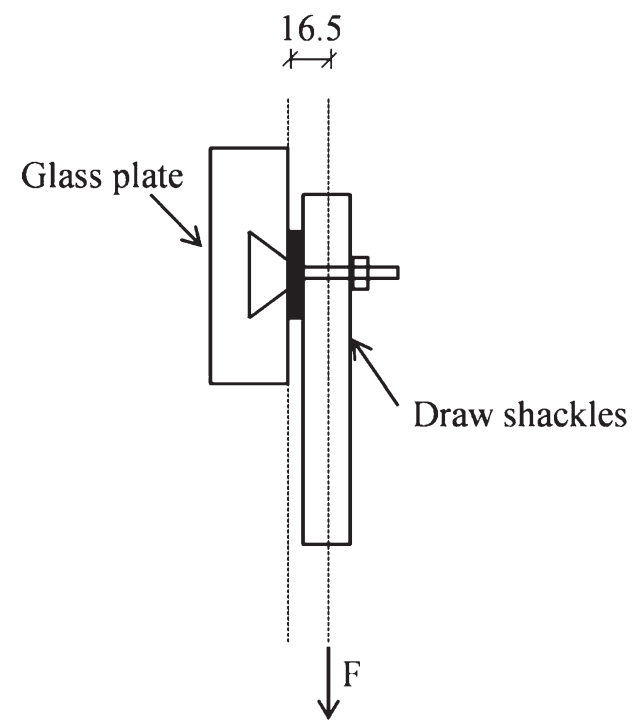

Fig. 9. Lever arm of the Fischer FZP-G-Z.

In order to calibrate the FE-model, the strains for two samples of each test series were measured during the tests along defined paths with strain gauges (Figs. 10-12).

The values for each test series were averaged to exclude measurement errors. The positions of the strain gauges for the tension, shear and diagonal pull tests were determined by preliminary FE calculation (Tibolt, Hechler, \& Odenbreit, 2013).

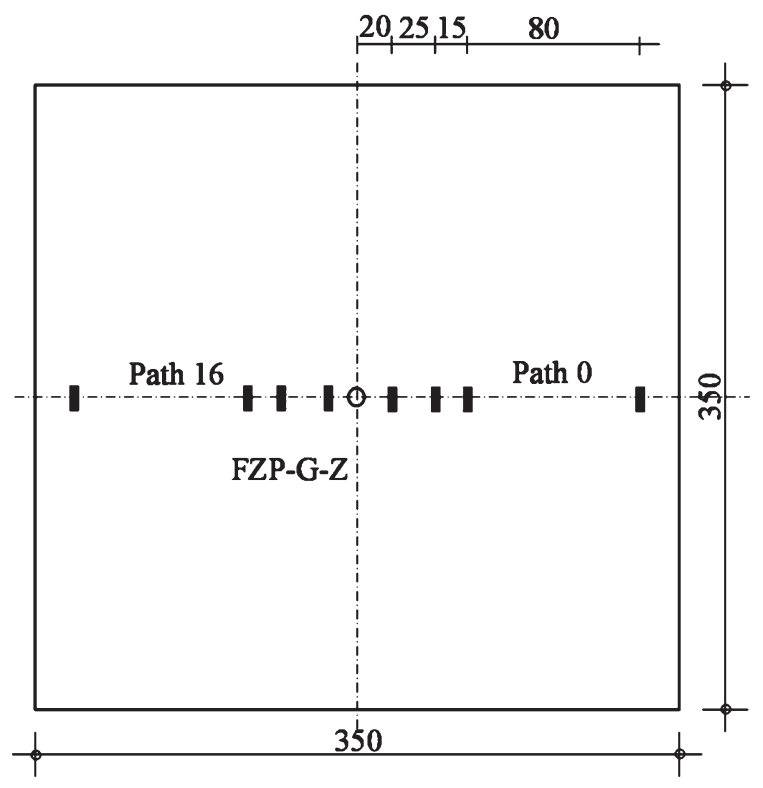

Fig. 10. Position of strain gauges for the tension tests $0^{\circ}$. 


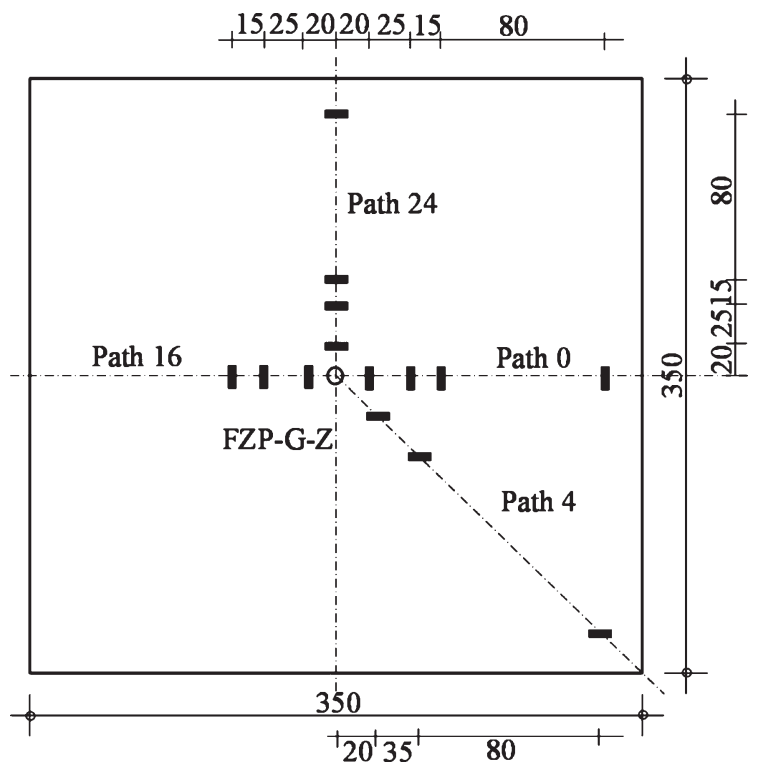

Fig. 11. Position of strain gauges for the diagonal pull tests $45^{\circ}$.

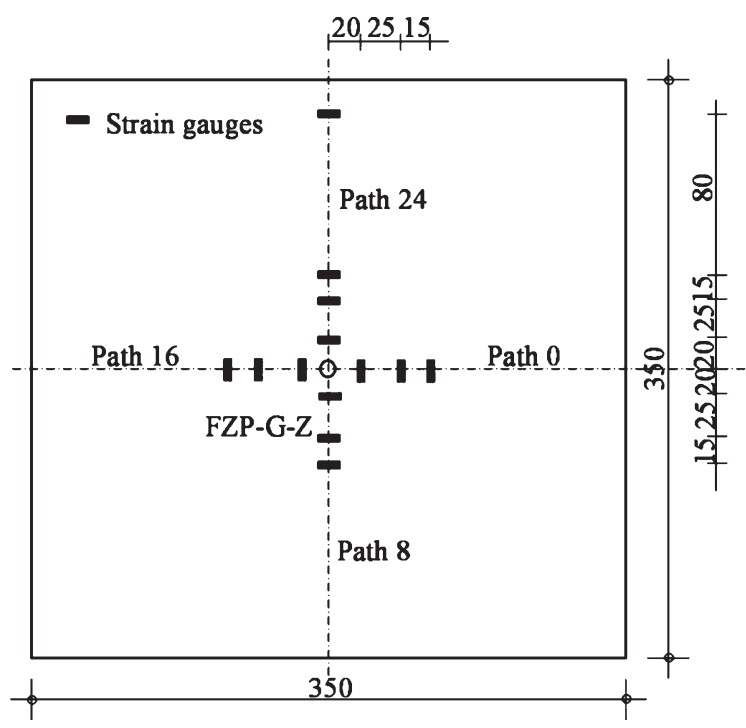

Fig. 12. Position of strain gauges for the shear tests $90^{\circ}$.

\subsection{Evaluation methodology and test results}

The tests were conducted until failure of the connection and the maximal bearing force was recorded for each test sample. The data have been statistically evaluated and the characteristic connection resistance and a corresponding partial safety factor have been derived (Tibolt, Hechler, \& Odenbreit, 2013). 
Table 2

Comparison of mean values of maximal forces

\begin{tabular}{lcccc}
\hline Test & $\begin{array}{c}\mathrm{t}_{\text {pane }} \\
(\mathrm{mm})\end{array}$ & $\begin{array}{c}\mathrm{F}_{\text {max,mean, test }} \\
(\mathrm{kN})\end{array}$ & $\begin{array}{c}\mathrm{F}_{\text {max,mean, IKI }} \\
(\mathrm{kN})\end{array}$ & $\begin{array}{c}\Delta \mathrm{F} \\
(\%)\end{array}$ \\
\hline $\mathrm{N}$ & 10 & 4.45 & 4.54 & 2 \\
& 12 & 5.27 & 5.75 & 9 \\
$\mathrm{Q}$ & 10 & 4.37 & 5.34 & 22 \\
& 12 & 6.67 & 7.84 & 18 \\
$\mathrm{~N}+\mathrm{Q}$ & 10 & 4.57 & 4.56 & $<1$ \\
& 12 & 5.59 & - & - \\
\hline
\end{tabular}

The mean values of the connection resistance are compared to the mean values of the test campaign at the 'IKI' (Beyer, 2007) (Table 2). For the tension and diagonal pull tests, the values are slightly lower than those of the 'IKI'. The difference is in all cases lower than $10 \%$. No indication about the results for the diagonal pull tests of the $12 \mathrm{~mm}$ plates are made by Beyer (2007). For the shear tests, high deviations between the own test results and the values of the 'IKI' are however noticed (about $20 \%$ ). In fact, the own shear tests were conducted with a lever arm of $16.5 \mathrm{~mm}$ (Section 5.2) compared to a lever arm of $14.5 \mathrm{~mm}$ at the 'IKI'. With regards to the sensitivity of the Fischer FZP-G-Z to moments, the higher lever arm explains the lower values in the own shear tests.

The Lilliefors hypothesis testing (Külmeyer, 2001) was applied to find a statistical distribution of the test data. Compared to the common Chi-squared test for goodness of fit, the Lilliefors testing is valid for a small number of test data. The 5 or 6 samples per test series (Table 1) consequently justify its use. As a result of the hypothesis testing, neither the normal nor the log-normal distribution could be rejected. Thus, both distributions could be assumed to determine the characteristic values (5\%fractile value). However, to exclude meaningless negative values for the resistance, the log-normal distribution has been retained for the statistically evaluation (Tibolt, Hechler, \& Odenbreit, 2013). An alternative to the log-normal distribution is the Weibull distribution. It is the most common distribution for resistance values in glass applications. In this paper, the log-normal distribution is however considered because the Weibull distribution is rejected by the Lilliefors hypothesis for the given test data.

The characteristic values of the connection resistance were determined according to the simplified method of DIN EN 1990, Annex D7 (2002). The method is based on the Bayes' procedure and delivers nearly the same results as standard stochastic procedures with a confidence coefficient of $75 \%$ (DIN EN 1990, 2002). The characteristic values are compared to the values in the general technical approval Z-70.2-122 (2007) (Table 3). Good accordance between the values is noticed. The highest deviation of $11 \%$ is observed for the diagonal pull test series. The small deviations could result from different test set-ups and differing statistical evaluation methods. The characteristic values for the shear resistance are lower than indicated in Z-70.2-122 (2007). The reason is the higher lever arm in the own tests. The difference (maximal 8\%) for the characteristic values is however lower than for the mean values (maximal 22\%), since the standard deviation of the own test data is lower than in the approval (Tibolt, 2015). As a conclusion, the values in Z-70.2-122 (2007) are confirmed and the designed test set-up allows simulating the load bearing tests of the FZP-G-Z with good reproducibility and accuracy.

The partial safety factor $\gamma_{R}$ for the connection resistance is derived on the basis of DIN EN 1990, Annex D7, (2002) and of a log-normal distribution: 
Table 3

Characteristic values of the connection resistance

\begin{tabular}{lcccc}
\hline Test & $\begin{array}{c}\mathrm{t}_{\text {pane }} \\
(\mathrm{mm})\end{array}$ & $\begin{array}{c}5 \%-\mathrm{F}_{\text {Test }} \\
(\mathrm{kN})\end{array}$ & $\begin{array}{c}5 \%-\mathrm{F}_{\mathrm{Z}-70.2-122} \\
(\mathrm{kN})\end{array}$ & $\begin{array}{c}\Delta \mathrm{F} \\
(\%)\end{array}$ \\
\hline $\mathrm{N}$ & 10 & 4.20 & 3.89 & 8 \\
& 12 & 4.73 & 4.60 & 3 \\
$\mathrm{Q}$ & 10 & 3.48 & 3.50 & -1 \\
& 12 & 5.97 & 6.50 & -8 \\
$\mathrm{~N}+\mathrm{Q}$ & 10 & 4.32 & 3.90 & 11 \\
& 12 & 5.32 & - & - \\
\hline
\end{tabular}

$$
\gamma_{R}=e^{\left[\left(\alpha_{R} \beta-k_{n}\right) \vartheta\right]}
$$

$v=$ variation coefficient for the log-normal distribution

$\alpha_{R}=$ sensitivity factor

$\beta=$ reliability index

$k_{n}=k_{n}$-factor

For an assumed service life of 50 years, Table C.2 in DIN EN 1990, Annex C6 (2002) indicates a target value of $\beta=3.8$. The sensitivity factor $\alpha_{R}$ is assumed to 0.8 . In this paper, the derivation procedure of the partial safety factor is exemplarily illustrated for the tension test series and a plate thickness of $12 \mathrm{~mm}$ (Table 4). The partial safety factor is $\gamma_{R}=1.1$.

The safety concept in DIN EN 1990 (2002) is the partial safety concept, while the concept in Z-70.2122 (2007) is based on the global safety concept. To allow a comparison to the defined safety level in Z-70.2-122 (2007), a global safety factor $\gamma^{*}=\gamma_{S} \cdot \gamma_{R}$ is determined according to Schneider (2001), where $\gamma_{S}=1.5$ is assumed for external actions (Table 5).

The global safety factor derived from the test campaign can be indicated with $\gamma^{*}=1.7$. A global safety factor of $\gamma=2.4$ is given in Z-70.2-122 (2007). As a result, the global safety concept in Z-70.2-122 (2007) is conservative. However, the global safety factor $\gamma^{*}$ is based on a small number of test samples and cannot be directly used in the design of the connection. Further the glass samples came all from only one producer and the pre-stress of the glass was done by only one refiner in one production

Table 4

Derivation of partial safety factor $\gamma_{R}$, Tension test series, $t=12 \mathrm{~mm}$

\begin{tabular}{lccccccc}
\hline $\begin{array}{l}\text { Sample } \\
{[-]}\end{array}$ & $\begin{array}{c}F_{\max } \\
{[\mathrm{N}]}\end{array}$ & $\begin{array}{c}\ln \left(F_{\max }\right) \\
{[-]}\end{array}$ & $\begin{array}{c}\mathrm{m}_{\mathrm{y}} \\
{[-]}\end{array}$ & $\begin{array}{c}\mathrm{s} \\
{[-]}\end{array}$ & $\begin{array}{c}\mathrm{V}_{\mathrm{x}} \\
{[-]}\end{array}$ & $\begin{array}{c}\mathrm{k}_{\mathrm{n}} \\
{[-]}\end{array}$ & $\begin{array}{c}\gamma_{\mathrm{R}} \\
{[-]}\end{array}$ \\
\hline $12-03$ & 4967.27 & 8.51 & 8.57 & 0.0493 & 0.0493 & 2.18 & 1.1 \\
$12-02$ & 4990.15 & 8.52 & & & & & \\
$12-01$ & 5211.72 & 8.56 & & & & & \\
$12-04$ & 5380.78 & 8.59 & & & & & \\
$12-05$ & 5506.77 & 8.61 & & & & & \\
$12-06$ & 5575.13 & 8.63 & & & & & \\
\hline
\end{tabular}


Table 5

Global safety factors $\gamma^{*}$

\begin{tabular}{lccc}
\hline Test & $\begin{array}{c}\mathrm{t}_{\text {pane }} \\
(\mathrm{mm})\end{array}$ & $\begin{array}{c}\gamma_{\mathrm{R}} \\
(-)\end{array}$ & $\begin{array}{l}\gamma^{*} \\
(-)\end{array}$ \\
\hline $\mathrm{N}$ & 10 & 1.1 & 1.7 \\
& 12 & 1.1 & 1.7 \\
$\mathrm{Q}$ & 10 & 1.1 & 1.7 \\
& 12 & 1.1 & 1.7 \\
$\mathrm{~N}+\mathrm{Q}$ & 10 & 1.1 & 1.7 \\
& 12 & 1.1 & 1.7 \\
\hline
\end{tabular}

shift. Though, the influence of production and refining on the glass strength is known (Beyer, 2007). The influence is not included in the partial safety factors derived in this paper and therefore they are only valid for samples tested with the set-up described in section 5.2 (Tibolt, Hechler, \& Odenbreit, 2013).

\section{Calibration of FE-model for the Fischer undercut anchor}

\subsection{FE-model of the Fischer FZP-G-Z}

A detailed numerical model of the Fischer FZP-G-Z has been implemented in the FE-software ABAQUS ${ }^{\circledR}$. The model accounts for the exact geometry of the borehole and the point fitting (Fig. 13).

The glass pane and the different components of the Fischer FZP-G-Z are modelled with solid elements. Contact properties are defined between the glass pane and the point fitting to simulate the uncoupling of the fitting from the glass. The material properties of the components and interlayers are adopted from a data sheet delivered by the Fischer-company (Table 6).

\subsection{Calibration process}

The verification and calibration process of the numerical model of the Fischer FZP-G-Z consists of four steps (Tibolt, Hechler, \& Odenbreit, 2013):
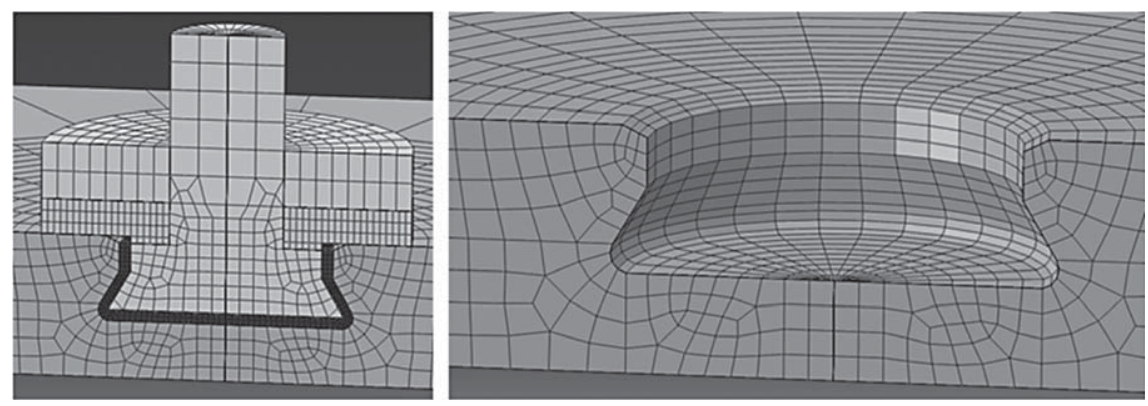

Fig. 13. FE-model of the Fischer FZP-G-Z and the undercut borehole. 
1. Verification of the element type and mesh quality for the glass pane.

2. Verification of the contact definition between the glass and the point fitting.

3. Verification of the rotational stiffness of the point fitting in the glass pane.

4. Calibration of the overall numerical model by strain comparison.

The element type and the mesh quality of the glass pane were checked by calculation of the stress concentration factor $k$ (Section 3.4) and comparison to the values given in Z-70.2-122 (2007). A glass plate with the detailed undercut borehole was modelled and subjected to pure bending (Fig. 14).

The stress concentration factor $k$, defined as the quotient of the maximal tensile stress at the borehole and the maximal global stress at the rim of the local area $(r=72.5 \mathrm{~mm})$, was numerically determined for two different edge distances of the borehole (Table 7). A good correspondence between the values is observed. In consequence, the chosen element type and the mesh generation are appropriate for the FE-model of the connection.

To verify the contact definition between the glass and the Fischer FZP-G-Z, so called 'load-stressdiagrams' were generated with the numerical model and compared to the diagrams of Beyer (2007).

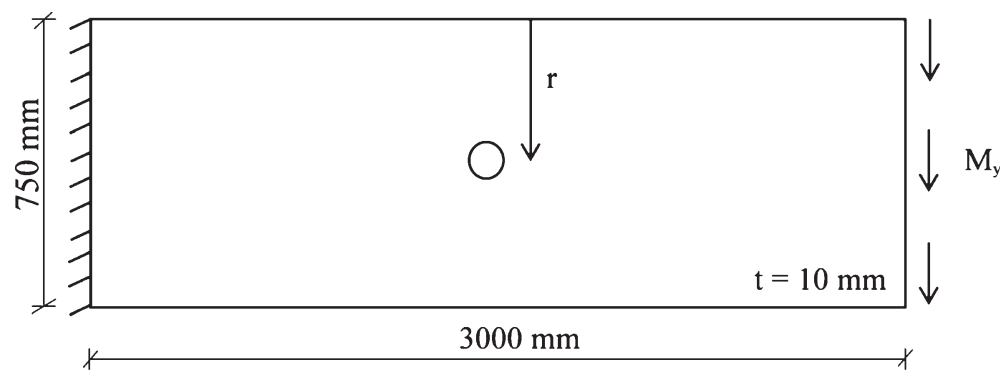

Fig. 14. Die plate for the determination of the stress concentration factor $k$.

Table 6

Material properties of the components

\begin{tabular}{lccc}
\hline Component & Material & $\begin{array}{c}\text { E-modulus } \\
\left(\mathrm{N} / \mathrm{mm}^{2}\right)\end{array}$ & $\begin{array}{c}\text { Poisson's ratio } \\
(-)\end{array}$ \\
\hline 1) Anchor & Stainless steel & 190000 & 0.3 \\
2) Spacer disk & Polyamide & 1000 & 0.4 \\
3) Round nut & Stainless steel & 190000 & 0.3 \\
4) Plastic plug & Polyurethane & 80 & 0.4 \\
\hline
\end{tabular}

Table 7

Stress concentration factors

\begin{tabular}{lccccr}
\hline$r$ & $\begin{array}{c}\sigma_{\max } \\
(\mathrm{N} / \mathrm{mm})\end{array}$ & $\begin{array}{c}\sigma_{72.5} \\
(\mathrm{~N} / \mathrm{mm})\end{array}$ & $\begin{array}{c}\mathrm{k}_{\text {num }} \\
(-)\end{array}$ & $\begin{array}{c}\mathrm{k}_{\mathrm{z}-70.2-122} \\
(-)\end{array}$ & $\begin{array}{r}\Delta \mathrm{k} \\
(\%)\end{array}$ \\
\hline 60 & 7.02 & 3.66 & 1.92 & 1.90 & 1 \\
90 & 5.83 & 3.72 & 1.57 & 1.60 & -2 \\
\hline
\end{tabular}




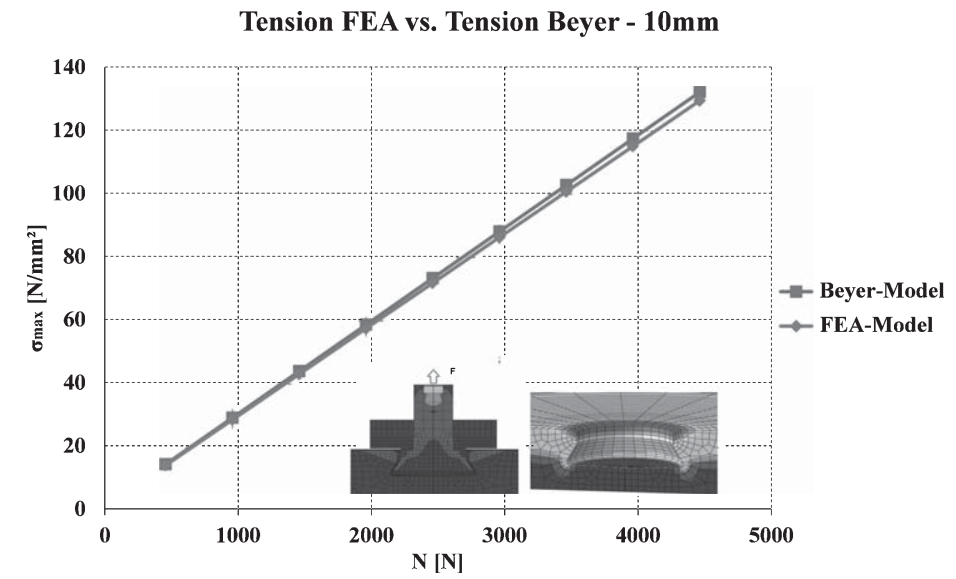

Fig. 15. Load-stress-diagram for the tension loads.

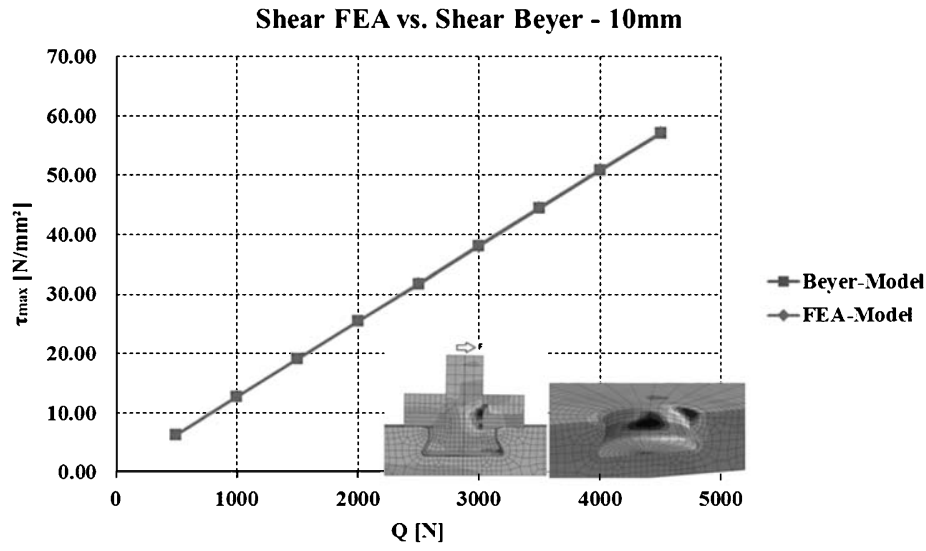

Fig. 16. Load-stress-diagram for the shear loads.

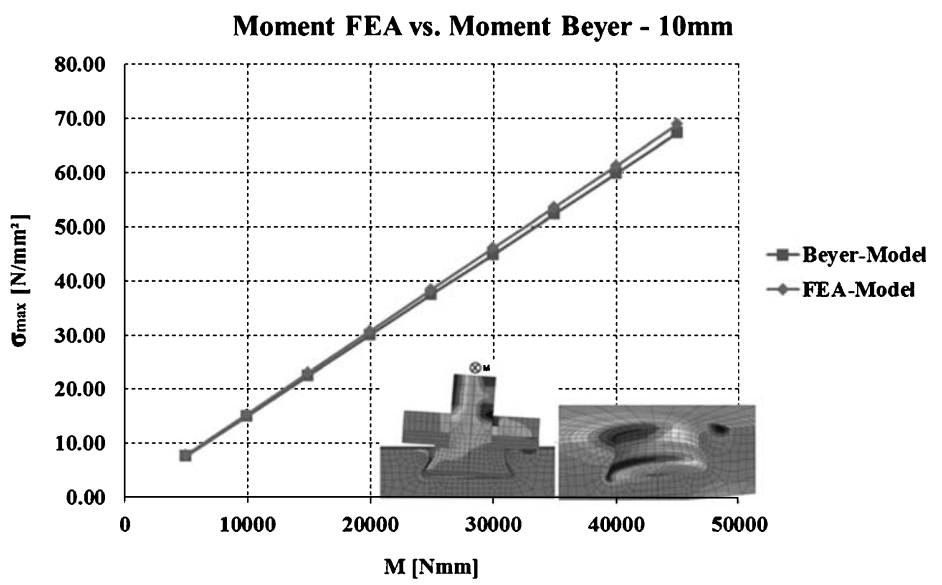

Fig. 17. Load-stress-diagram for the moments. 


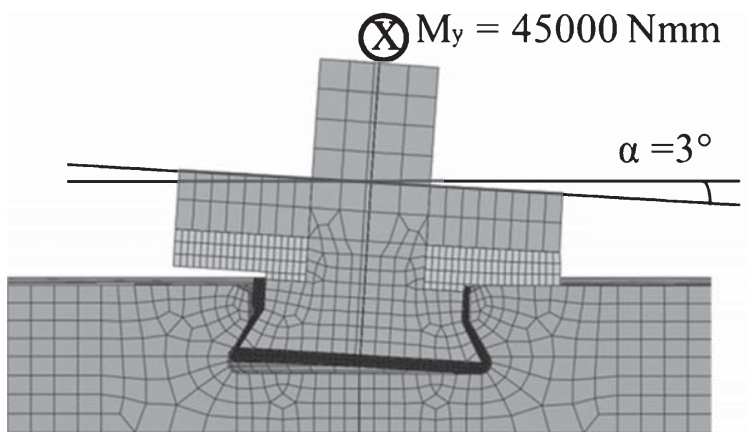

Fig. 18. Measured rotation angle of the Fischer FZP-G-Z.

Table 8

Rotational stiffness of the Fischer FZP-G-Z

\begin{tabular}{lccc}
\hline $\begin{array}{l}\text { Thickness } \\
(\mathrm{mm})\end{array}$ & $\begin{array}{c}\mathrm{k}_{\mathrm{d}, \text { num }} \\
\left(\mathrm{Nm} /{ }^{\circ}\right)\end{array}$ & $\begin{array}{c}\mathrm{k}_{\mathrm{d}, \exp } \\
\left(\mathrm{Nm} /{ }^{\circ}\right)\end{array}$ & $\begin{array}{c}\Delta \mathrm{k} \\
(\%)\end{array}$ \\
\hline 10 & 14.52 & 15.00 & -3.2 \\
12 & 15.00 & 15.00 & 0 \\
\hline
\end{tabular}

The load-stress-diagrams relate the forces in the point fitting to the corresponding maximal local tensile stress peak occurring at the borehole (Beyer, 2007). The $10 \mathrm{~mm}$-thick glass plate samples of the component tests were numerically modelled and the point fitting was subjected to tension, shear and bending. The load-stress diagrams were generated and compared to those of Beyer (2007), (Figs. 15-17).

The diagrams perfectly match and the maximal deviation is only $2 \%$. As a conclusion, the contact definitions are verified.

The rotation stiffness of the Fischer FZP-G-Z is numerically determined with the FE-model of the point fitting and compared to the experimental values in Z-70.2-122 (2007). A moment of $M_{y}=45,000$ $\mathrm{Nmm}$ was applied to the FZP-G-Z in the FE-model for the $10 \mathrm{~mm}$ - and the $12 \mathrm{~mm}$-thick plates and the rotation angle was measured (Fig. 18).

The stiffness was calculated according to Hooke's law and compared to the values in Z-70.2-122 (2007), (Table 8). Good correlation between the numerical and experimental values is observed. Thus, the FE-model correctly takes into account the rotational spring stiffness of the FZP-G-Z in $10 \mathrm{~mm}$ and $12 \mathrm{~mm}$ thick glass plates.

This verified FE-model of the point fitting was used to define the position of the strain gauges in the component tests (Section 5.2).

The FE-model was finally calibrated by simulating the component tests and comparing the numerical to the measured strains for a force of $2500 \mathrm{~N}$ in the point fitting. In this paper, the comparison is exemplarily shown for the tension tests at a tension load of $F=2500 \mathrm{~N}$ (Fig. 19).

The good correspondence of the calculated and measured strains proofs the validity of the FE-model of the Fischer FZP-G-Z. 


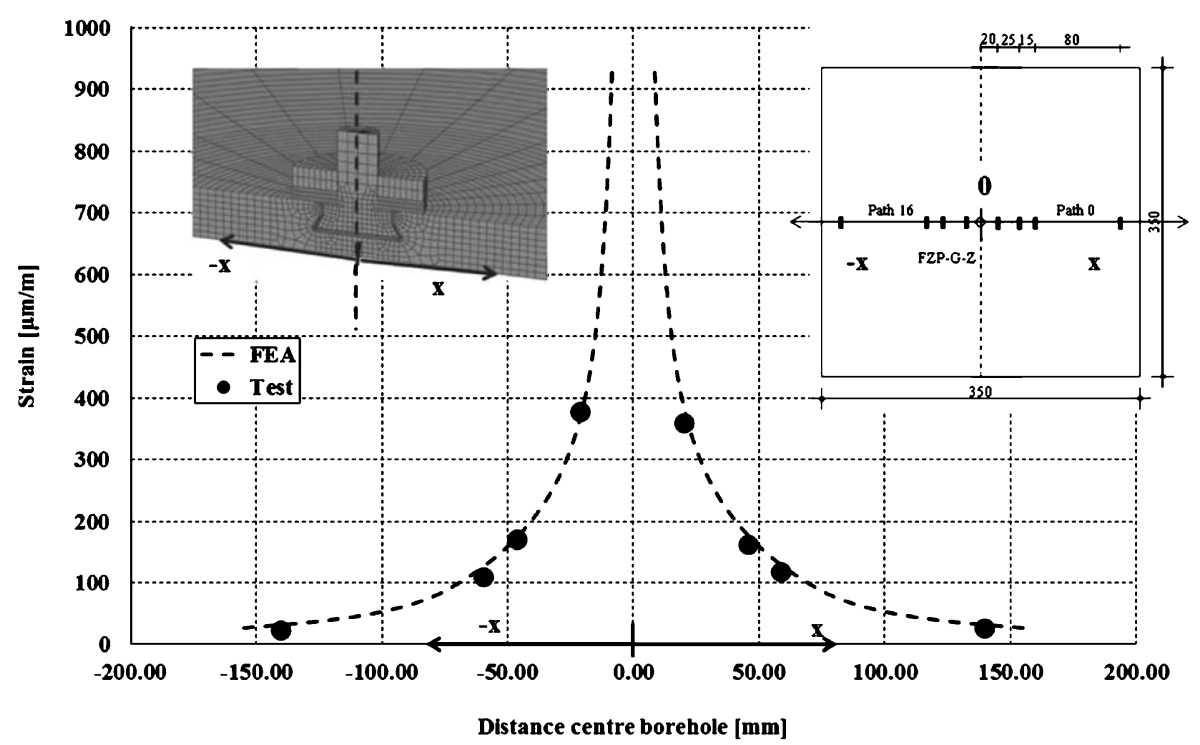

Fig. 19. Comparison of numerical and experimental strains for the tension test at a load of $\mathrm{F}=2500 \mathrm{~N}$.

\section{The Fischer FZP-G-Z in insulation glass}

\subsection{Objectives}

The verified and calibrated model of the Fischer FZP-G-Z is implemented in a selected insulation glass unit. The aim consists in investigating the influence of the edge bond stiffness and geometry on the stress peak at the borehole. Objective of the investigation in this paper is the comparison of the stress peak location in single and insulation glazing in order to readopt the size of the local area. Additionally, the dependency of the stress peaks on the edge bond stiffness and geometry is analysed.

\subsection{FE-models of point fitted insulation glass unit}

A squared point fitted insulation glass unit with the dimensions of $1200 \mathrm{~mm} \times 1200 \mathrm{~mm}$ has been implemented in ABAQUS ${ }^{\circledR}$. Figure 20 shows its assembly. The edge distances of the Fischer FZP-G-Z are indicated in Table 9.

Four common edge seal configurations were investigated (Fig. 21; Table 10).

The material properties for the primary sealant, secondary sealant and the spacer are given in Table 11.

The primary sealant is made of PIB. According to Schäfer (2002), the Young's modulus of PIB falls within a range of $0.7 \cdot 10^{-6}$ and $1.5 \cdot 10^{-6} \mathrm{~N} / \mathrm{m}^{2}$. Thus, independently from the loading rate, the material is very soft and it can be assumed that it has no structural function (Van den Bergh, Hart, Jelle \& Gustavsen, 2013). In the numerical model, the behaviour of the PIB was described with a linear elastic material law with a Young's modulus of $\mathrm{E}=1 \cdot 10^{-6} \mathrm{~N} / \mathrm{mm}^{2}$ (Table 11). 


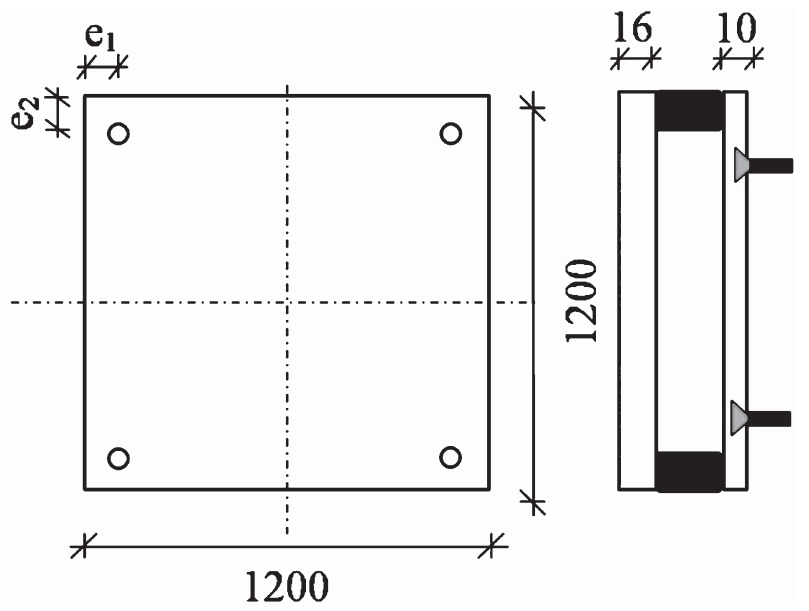

Fig. 20. Dimensions and assembly of the numerical insulation glass model.

Table 9

Edge distances of the Fischer FZP-G-Z

\begin{tabular}{ccc}
\hline No. & $\begin{array}{c}\mathrm{e}_{1} \\
(\mathrm{~mm})\end{array}$ & $\begin{array}{c}\mathrm{e}_{2} \\
(\mathrm{~mm})\end{array}$ \\
\hline 1 & 60 & 60 \\
2 & 90 & 90 \\
3 & 150 & 150 \\
4 & 200 & 200 \\
\hline
\end{tabular}

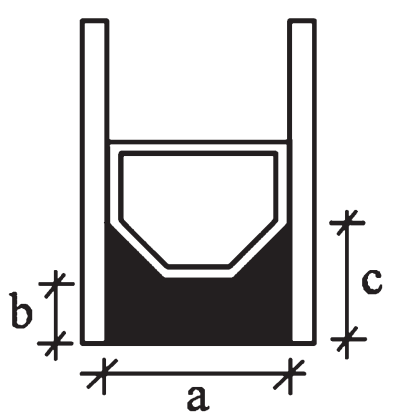

Fig. 21. Edge seal configurations.

Structural silicone is used for the secondary sealant. Different linear elastic material laws for silicone, given in the data sheets of the producers (Dow Corning, 2004; Sika, 2012; Bostik, 2008), were implemented in the numerical model. The values for the Young's modulus are experimentally determined by the producers according to ETAG 002 (2012). The values correspond to the chord modulus based on the two specific strain values $\varepsilon_{1}=0.05 \%$ and $\varepsilon_{2}=0.25 \%$. In this case, the time dependency of 
Table 10

Edge seal configurations

\begin{tabular}{lccc}
\hline Config. & $\begin{array}{c}\mathrm{a} \\
(\mathrm{mm})\end{array}$ & $\begin{array}{c}\mathrm{b} \\
(\mathrm{mm})\end{array}$ & $\begin{array}{c}\mathrm{c} \\
(\mathrm{mm})\end{array}$ \\
\hline 1 & 12 & 6 & 13 \\
2 & 12 & 16 & 23 \\
3 & 16 & 6 & 13 \\
4 & 16 & 16 & 23 \\
\hline
\end{tabular}

Table 11

Material laws for edge seal components

\begin{tabular}{lcccc}
\hline Component & Material & Law & $\begin{array}{c}v \\
(-)\end{array}$ & $\begin{array}{c}\text { E-modulus } \\
\left(\mathrm{N} / \mathrm{mm}^{2}\right)\end{array}$ \\
\hline Spacer & Stainless steel & Linear elastic & 0.3 & 210000 \\
& Aluminium & Linear elastic & 0.3 & 70000 \\
& Polycarbonate & Linear elastic & 0.45 & 2000 \\
& Polypropylene & Linear elastic & 0.45 & 1500 \\
Secondary sealant & Silicone & Linear elastic & 0.48 & 0.5 \\
& & & 0.48 & 1 \\
& & & 0.48 & 2.4 \\
& & & 0.48 & 4.8 \\
Primary sealant & & Dias & - & - \\
\hline
\end{tabular}

the silicone is not considered. For the linear elastic material laws of the rubbery polymers, a value of 0.48 is used for the Poisson's ratio. Theoretically, a value of 0.5 would be appropriated to reproduce the isochoric behaviour. However, the numerical calculation does not converge with a value of 0.5 . Furthermore, O'Hara (1983), by using the hydrostatic method, found Poisson's ratio in the range of 0.48 to 0.49 for small strains. Finally, the stress peak values at the borehole have been numerically determined for different Poisson's ratio values in the range of 0.48 to 0.49 for the silicone sealant and the PIB, and no influence on the stress peak has been noticed. In consequence, a value of 0.48 for the Poisson's ratio of silicone and the PIB is justified to investigate the influence of the edge bond stiffness on the stress peak at the borehole. In addition to the linear elastic material laws for the silicone, a more precise material law for the structural silicone 'Dow Corning 993' (Dow Corning, 2004) was inserted in the main software with a subroutine. It has been experimentally derived by Dias (2013) at the University of Luxembourg and is based on the energy potential from tension, compression, shear and oedometric tests. The material law takes into account: the continuous and discontinuous (Mullin's effect) damage of the silicone, under cyclic loading, the influence of the loading rate on the initial stiffness of the silicone and the stress softening of the silicone under long-term loading. The influence of these parameters is considered in the material constants of the law (Dias, 2013). 


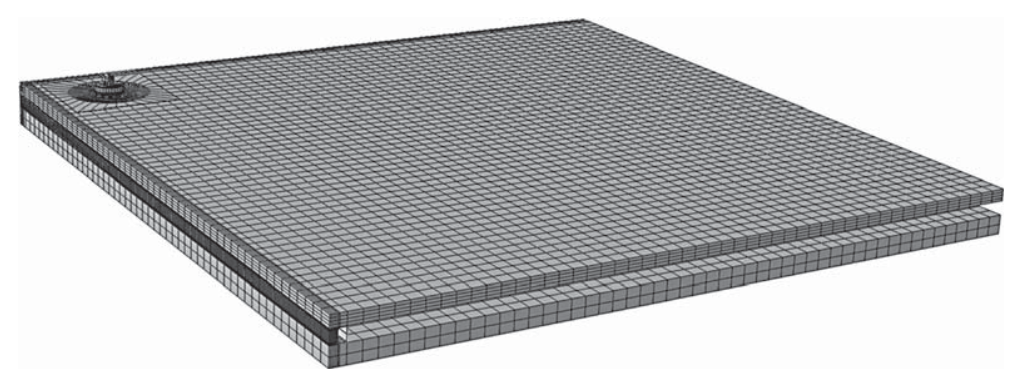

Fig. 22. 3D-FE-model of the point-fitted insulation glass unit.

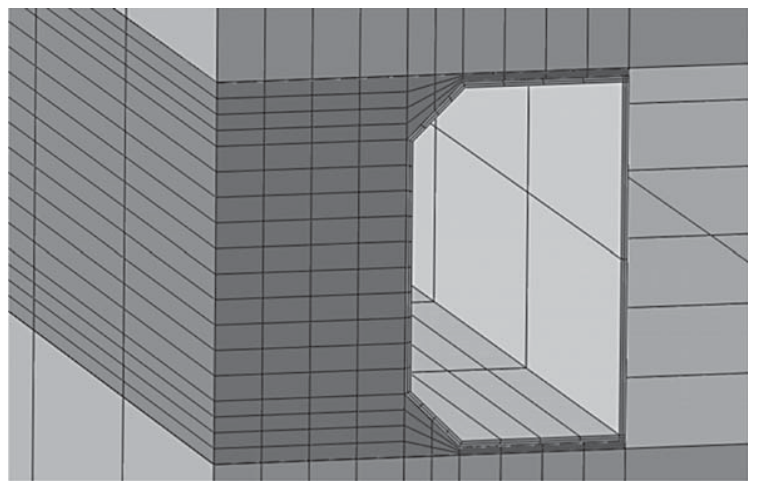

Fig. 23. 3D-FE-model of the edge seal with the primary sealant PIB.

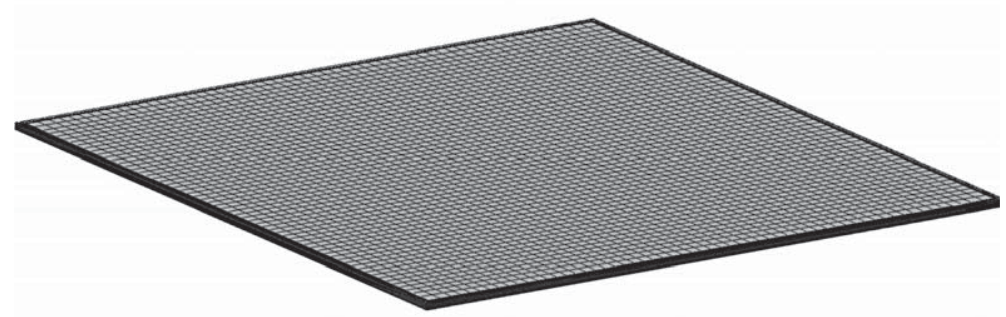

Fig. 24. 2D-FE-model of the point-fitted insulation glass unit.

For the spacer, four different materials were used: aluminium, stainless steel, polycarbonate (PC) and polypropylene (PP).

Two different models were designed (Tibolt, Hechler, \& Odenbreit, 2013):

(1) A first 3D model with solid elements (Fig. 22-23). The model exactly takes into account the geometry of the borehole.

(2) For the second 2D model (Fig. 24), shell elements are used for the two glass panes and the Fischer FZP-G-Z point fitting is replaced by spring elements with its corresponding stiffness (Z-70.2-122, 2007). 
Table 12

Climate loads (DIN 18008-1, 2010)

\begin{tabular}{lccc}
\hline Climate load & $\begin{array}{c}\Delta T \\
(\mathrm{~K})\end{array}$ & $\begin{array}{c}\Delta \mathrm{p} \\
\left(\mathrm{kN} / \mathrm{m}^{2}\right)\end{array}$ & $\begin{array}{c}\Delta \mathrm{H} \\
(\mathrm{m})\end{array}$ \\
\hline Winter & -25 & +4.0 & -300 \\
Summer & +20 & -2.0 & +600 \\
\hline
\end{tabular}

Table 13

Resulting loads, $t_{\text {outer }}=16 \mathrm{~mm}, \mathrm{t}_{\text {inner }}=10 \mathrm{~mm}$

\begin{tabular}{lcc}
\hline Pane & Outer pane & Inner pane \\
\hline$p_{\text {res }}\left(\mathrm{kN} / \mathrm{m}^{2}\right)$ & 0.3 & -2.8 \\
\hline
\end{tabular}

The borehole is not generated in the 2D model. The edge bond is modelled with solid elements as for the 3D-model. The second model corresponds to the simple 2D-model proposed by Beyer (2007) for the design of single and laminated point fitted glass. Only a quarter of the insulation glass unit was modelled in order to save calculation time.

\subsection{Loads acting on the insulation glass unit}

The highest stress peak at the borehole occurs for the extreme climate load case 'winter' according to DIN 18008-1 (2010) (Table 12) in combination with a wind suction load acting on the outer glass pane. The climate load is converted to resulting surface loads acting on each glass pane by means of a climate load model for point fitted insulation glass with undercut anchors (Tibolt, Hechler, \& Odenbreit, 2014). A wind suction load of $p_{e, w}=-2.5 \mathrm{kN} / \mathrm{m}^{2}$ is applied on the outer glass pane and superposed with the climate loads. The resulting loads acting on each glass pane in the FE-model are given in Table 13.

\subsection{Influence of the edge seal stiffness on the stress peak}

Common edge seals are composed of three elements: the primary sealant, the spacer and the secondary sealant. The stiffness of the edge seals consequently depends on the stiffness of each element. In this section, the influence of the rigidity of each element on the stress peak is investigated.

\subsubsection{Location of the stress peak}

For the loading case and the geometry of the IGU that are investigated in this paper, the stress peak is located at the rim of the borehole (Fig. 25-26).

\subsubsection{Influence of the spacer stiffness}

The stress peaks were calculated for the spacer materials indicated in Table 11.

Figure 27 exemplary shows the results for the edge seal configuration 1 with a Young's modulus of $\mathrm{E}=0.5 \mathrm{~N} / \mathrm{mm}^{2}$ for the secondary sealant and an edge distance of $60 \mathrm{~mm}$. 


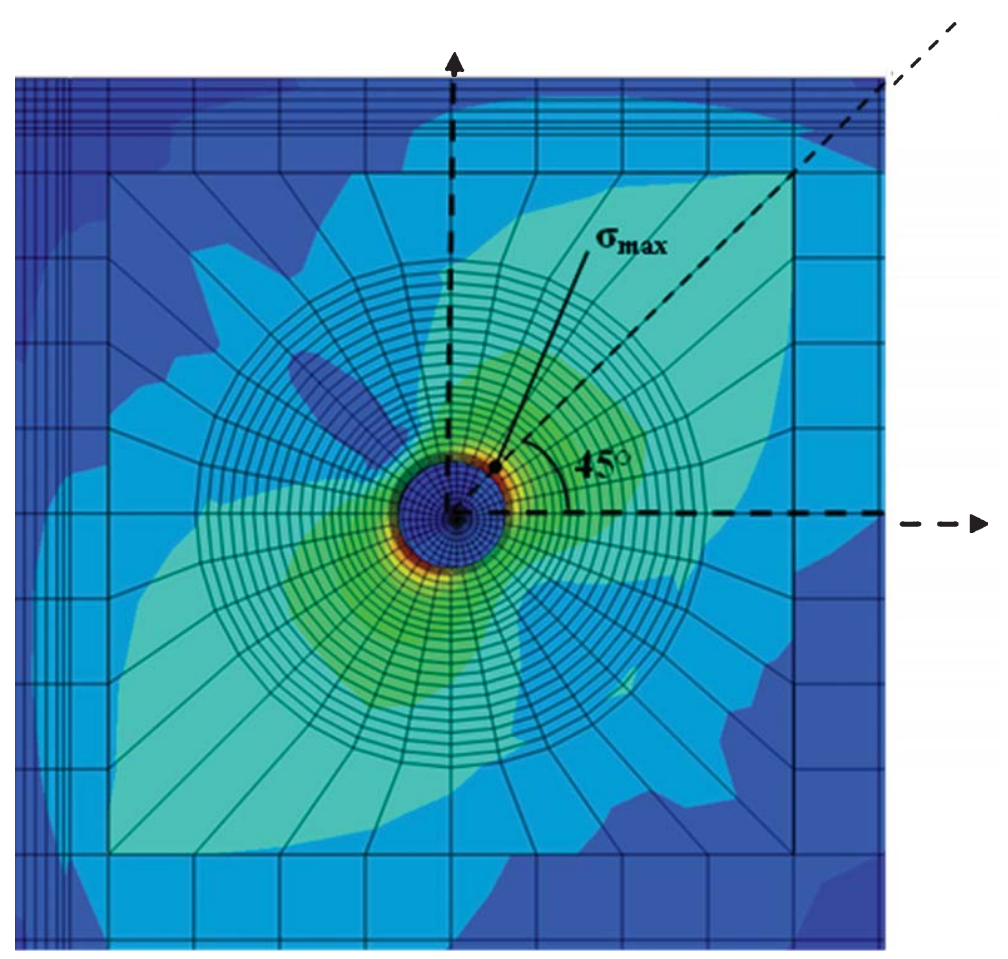

Fig. 25. Location of the stress peaks at the borehole.

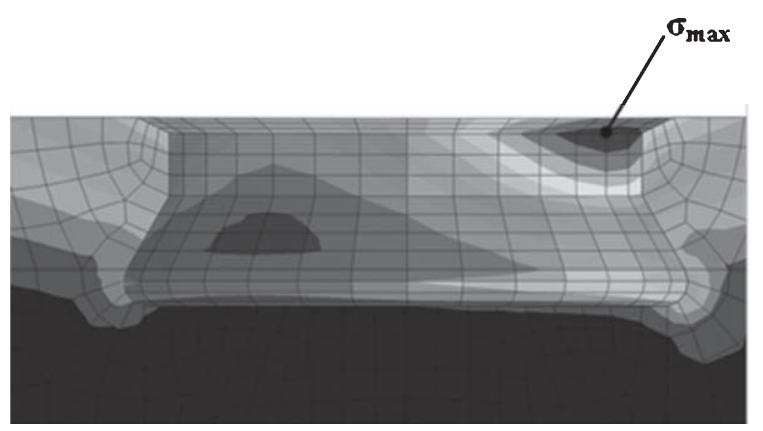

Fig. 26. The stress peak at the rim of the borehole.

The influence of the spacer stiffness on the stress peak is marginally. The maximal deviation only amounts $1.5 \%$.

A comparison of the stress distributions along the radial path of the maximal stress peak for the different spacer materials does not reveal a dependency of the stresses near the borehole on the spacer stiffness (Fig. 28).

A small difference $(<8 \%)$ in the stress distributions from up a distance of nearly $35 \mathrm{~mm}$ from the borehole centre is however observed. This is due to the proximity to the edge, where the stress state is sensitive to the edge seal stiffness. 


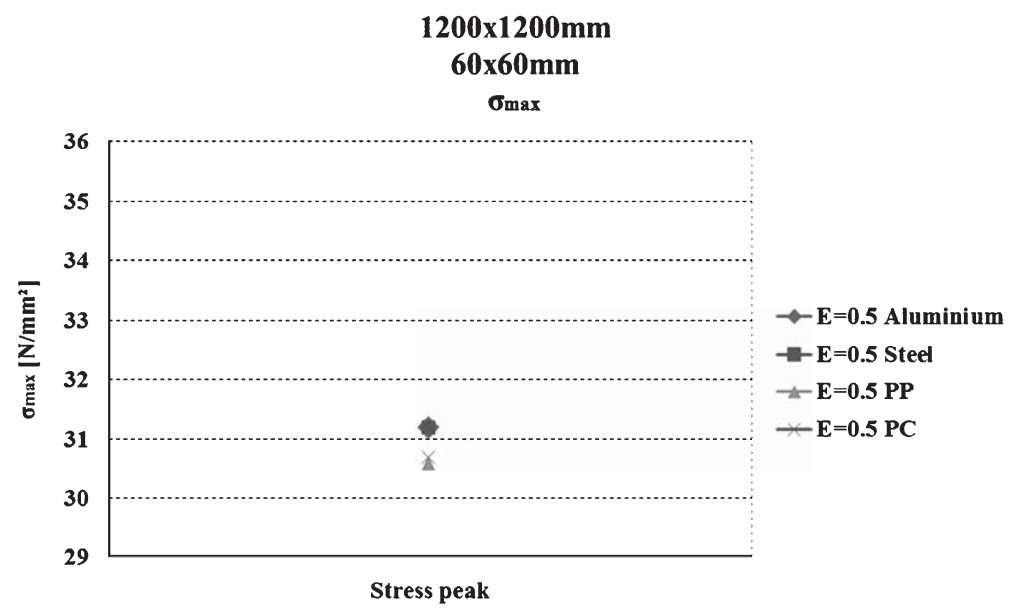

Fig. 27. Stress peaks at the borehole for different spacer materials.

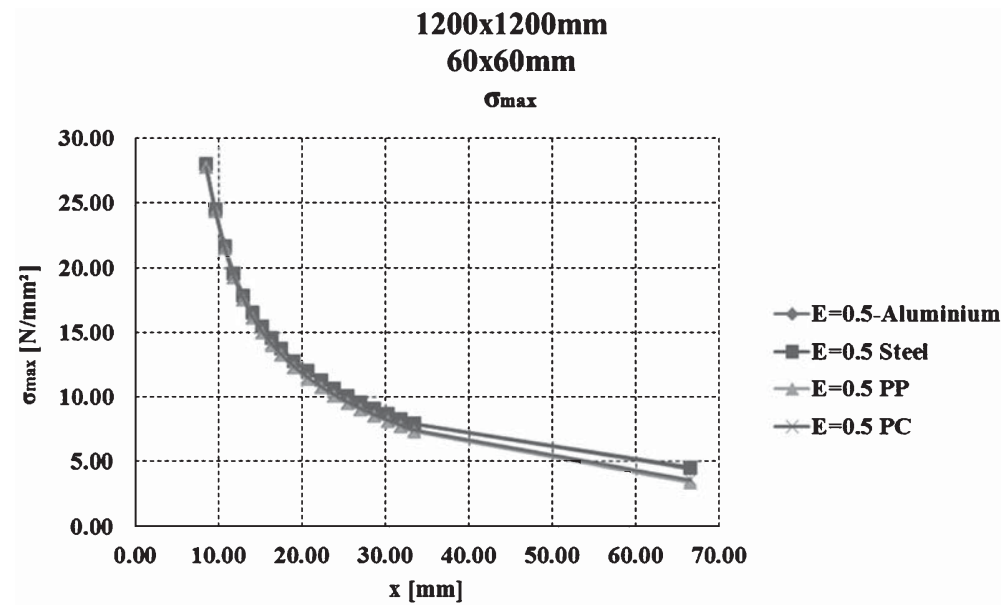

Fig. 28. Stress distribution along the radial path of the maximal stress peak for different spacer materials.

The same results are observed for the other edge seal configurations, secondary sealant material laws and edge distances of the Fischer FZP-G-Z (Tibolt, 2015).

Consequently, the influence of the spacer stiffness on the stress peak at the borehole can be neglected.

\subsubsection{Influence of the primary sealant PIB}

To analyse the influence of the primary sealant on the stress peak at the borehole, the stress peaks were calculated with two different FE-models of the edge seal. On one hand a FE-model accounting for the soft material law of the PIB (Table 11) and on the other hand a numerical model without the primary sealant (Fig. 29).

The stress peaks are shown in Fig. 30. 


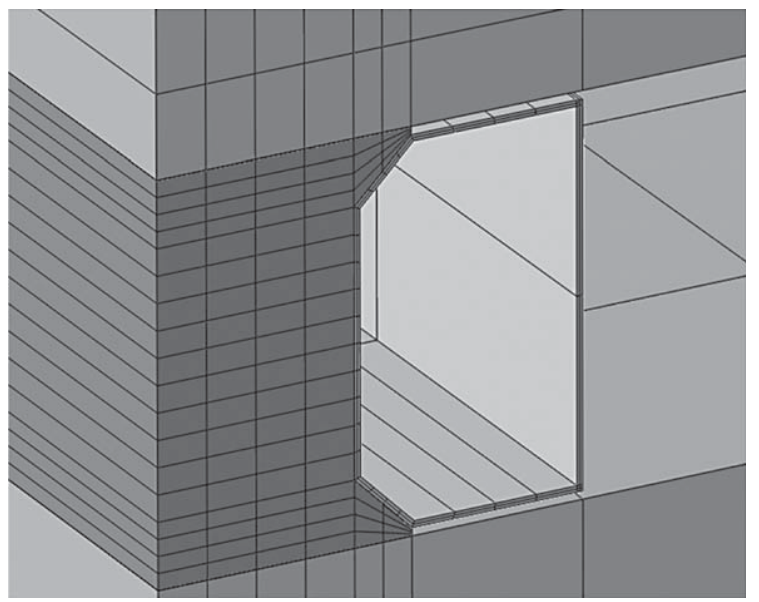

Fig. 29. 3D-FE-model of the edge seal without the primary sealant PIB.

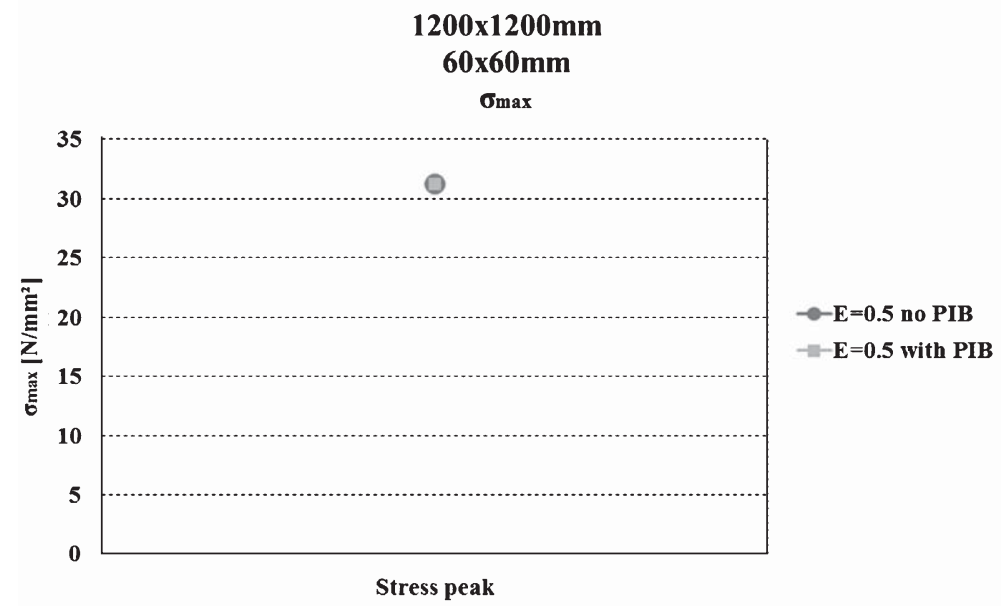

Fig. 30. Stress peaks at the borehole for an edge seal configuration with PIB and a configuration without PIB.

They were determined for edge seal configuration 1, a Young's modulus of $E=0.5 \mathrm{~N} / \mathrm{mm}^{2}$ and an edge distance of $60 \mathrm{~mm}$. The peaks are identic. Additionally, the stress distributions near the borehole are almost the same (Fig. 31).

Finally, the influence of the PIB on the stress peak is insignificant.

\subsubsection{Influence of the secondary sealant stiffness}

The stress peaks were determined for the different edge seal configurations, edge distances and silicone material laws. The spacer material was in all cases aluminium.

Independently of the edge seal configuration and of the edge distance of the point fitting, the stress peak increases with increasing stiffness of the secondary sealant (Fig. 32). 


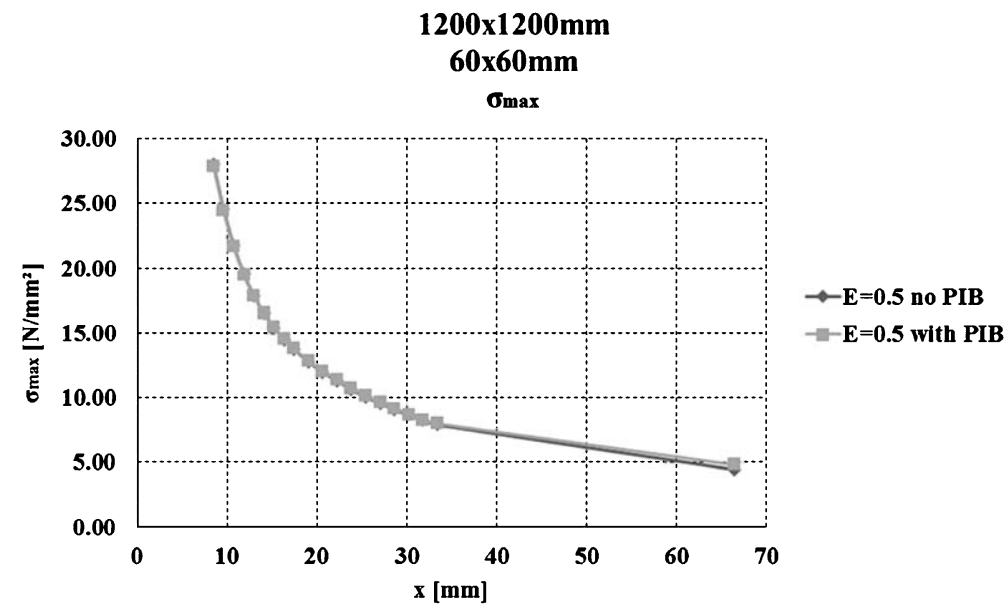

Fig. 31. Stress distribution along the radial path of the maximal stress peak for an edge seal configuration with PIB and a configuration without PIB.

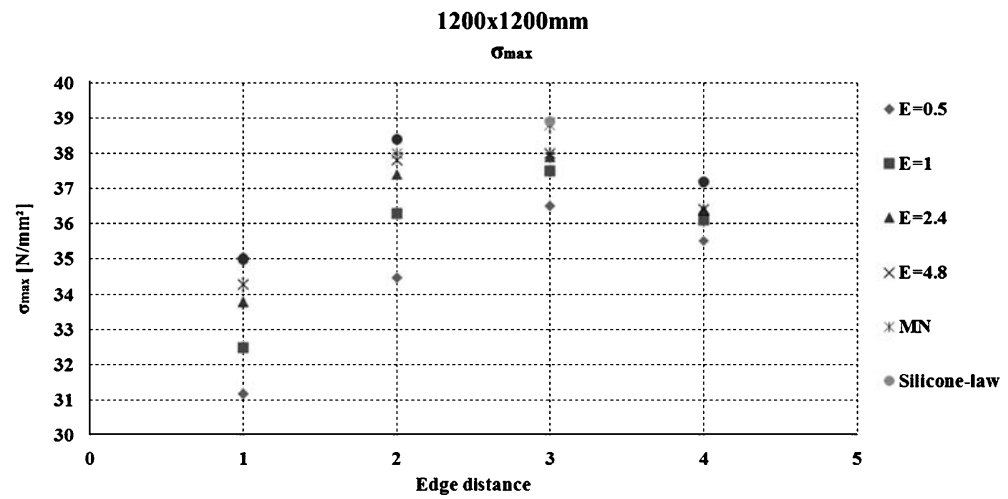

Fig. 32. Influence of the edge seal stiffness and the edge distance of the point fitting on the stress peak at the borehole.

The lowest stress peak is obtained with a Young's modulus of $E=0.5 \mathrm{~N} / \mathrm{mm}^{2}$ and the highest stress peak is noticed for the hyper-elastic material law of Dias (2013). The difference between the lowest and highest stress peak value strongly depends on the edge distance of the point fitting. The higher the edge distance, the lower the difference. The dependency is observed for every edge seal configuration. For instance, the difference amounts $12 \%$ for an edge distance of $60 \mathrm{~mm}$ and only $4.8 \%$ for an edge distance of $200 \mathrm{~mm}$ in the case of edge seal configuration 1 . The reason is the dependency of the load transfer mechanism of the Fischer FZP-G-Z from the sealant stiffness. For low edge distances, the transfer mechanism varies in function of the secondary sealant stiffness and so do the stress peak. However, the transfer mechanism is only marginally influenced by the sealant stiffness for high edge distances and the stress peak solely varies weakly.

The stress peak increases between the edge distances of $60 \mathrm{~mm}$ and $150 \mathrm{~mm}$ and decreases from $150 \mathrm{~mm}$ to $200 \mathrm{~mm}$. This behaviour is observed for every silicone material law and edge seal 


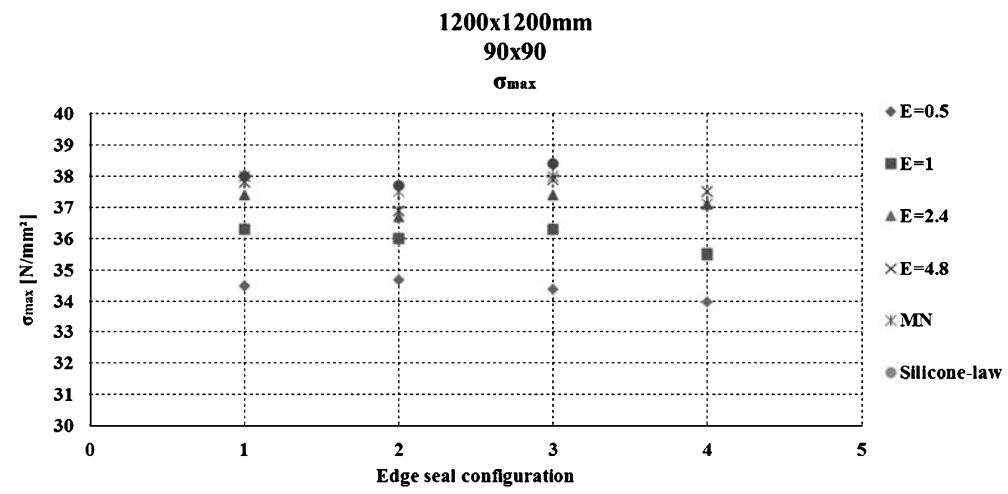

Fig. 33. Influence of the edge seal geometry on the stress peak at the borehole.

configuration. It can be explained by the dependency of the load transfer mechanism of the point fitting from the edge distance.

\subsection{Influence of the edge seal geometry on the stress peak}

The stress peaks were determined for the four common edge seal geometries indicated in Table 10 and the edge distances given in Table 8. The different material laws (Table 6) for the silicon sealant were applied. As the material of the spacer has no influence on the stress peak (Section 7.4.2), aluminium has been chosen for the spacer in all cases. For the edge distance of $60 \mathrm{~mm}$, the edge seal configurations 2 and 4 have not been investigated, since the two combinations are not common in practice.

Independently from the given edge distance and silicone material law, nearly no deviations are observed between the edge seal configurations 1 and 3 and the edge seal configurations 2 and 4 (Fig. 33).

The maximal difference is less than $2 \%$. Thus, the height of the secondary sealant obviously has no influence on the stress peak at the borehole.

A comparison of the edge seal configurations 1 and 2, respectively 3 and 4 does no reveal significant differences for the stress peaks (Fig. 33). All the deviations are less than $2 \%$. No influence of the silicone sealant thickness on the stress peak is detected.

Consequently, the influence of the secondary sealant thickness and height on the stress peak is marginally for the investigated edge bond geometries and can finally be neglected.

\subsection{Comparison between the 3D-and 2D-FE-model}

By means of the 3D-FE-model (solid elements, sophisticated edge bond characterization and exact borehole geometry), the radial stress distribution among the path of the stress peak at the borehole were determined. These stresses were then compared to the distribution calculated by the 2D-FEmodel (shell elements for glass panes and no borehole).

Both distributions coincided with high accuracy at a minimal distance of about $r=45 \mathrm{~mm}$ (Fig. 34), independently of the edge bond stiffness and the edge distances of the Fischer FZP-G-Z. The distance of 
SOLID-SHELL

$60 \times 60 \mathrm{~mm}$

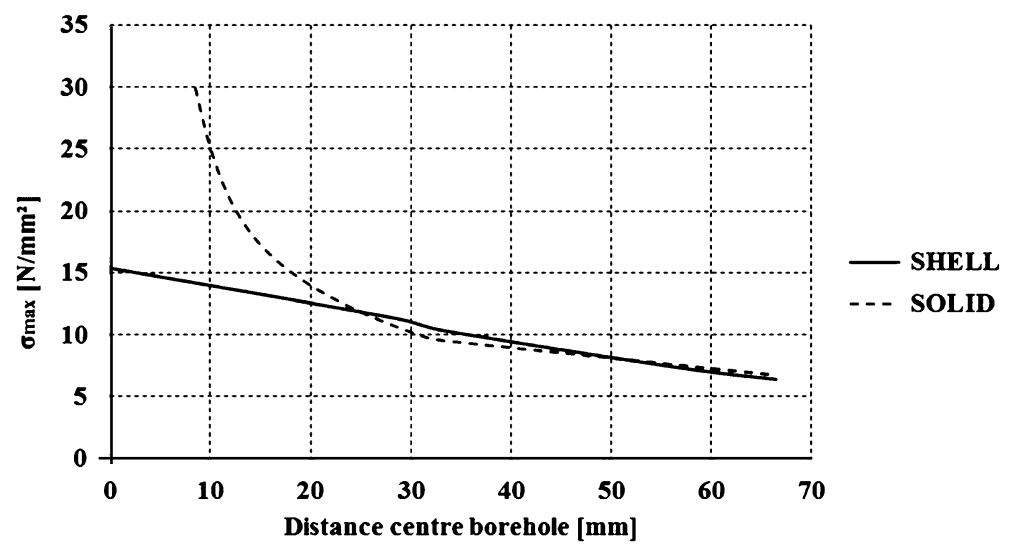

Fig. 34. Comparison of stress distribution with solid and shell elements.

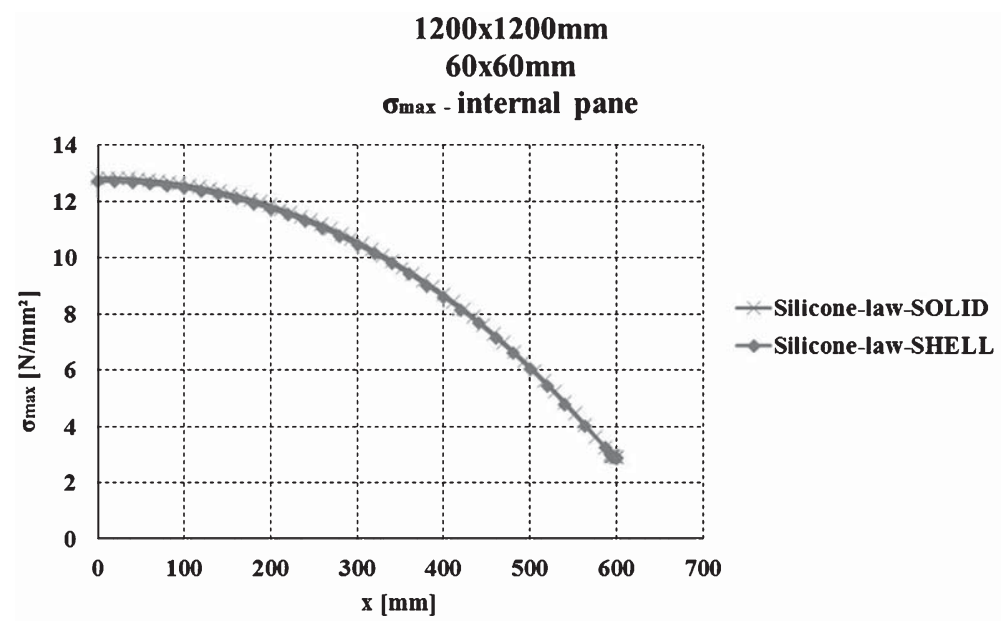

Fig. 35. Comparison of the stress distribution in the mid-span of the internal pane with solid and shell elements.

$r=45 \mathrm{~mm}$ exactly corresponds to three times the borehole diameter $(\mathrm{d}=15 \mathrm{~mm})$ of the Fischer FZP-G-Z and is in accordance with the Saint-Venant's Principle. Moreover, a comparison of the principal stresses in the mid-span of the inner and outer glass panes (Fig. 35-36) revealed the high correspondence between the 3D- and 2D-FE-model.

In consequence, the 2D-FE-model of the insulation glass unit is able to correctly simulate the stress state in the glass pane for the different edge distances and edge bond configurations. 


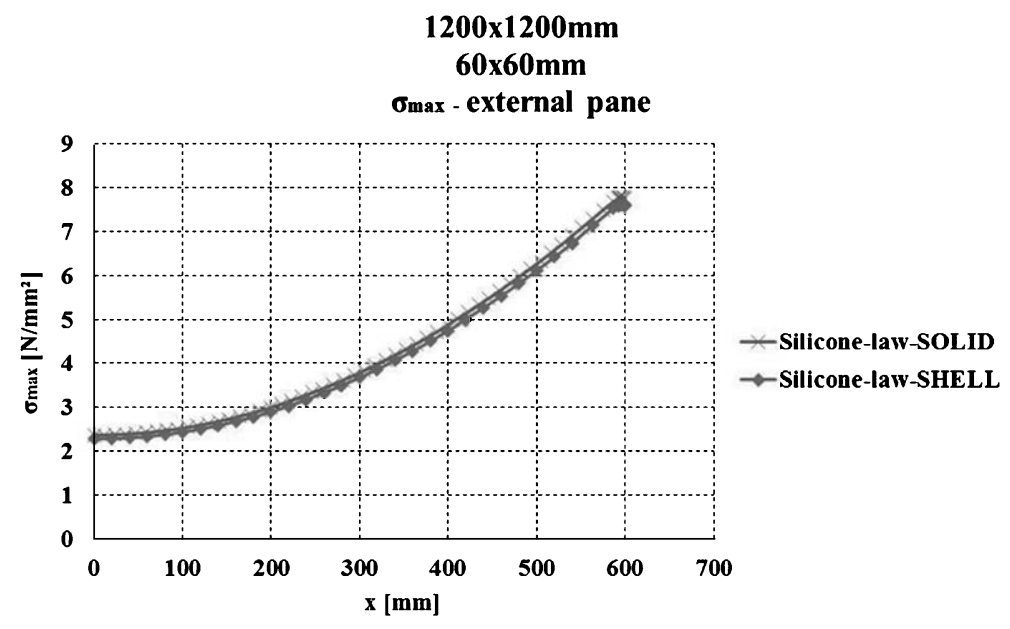

Fig. 36. Comparison of the stress distribution in the mid-span of the external pane with solid and shell elements.
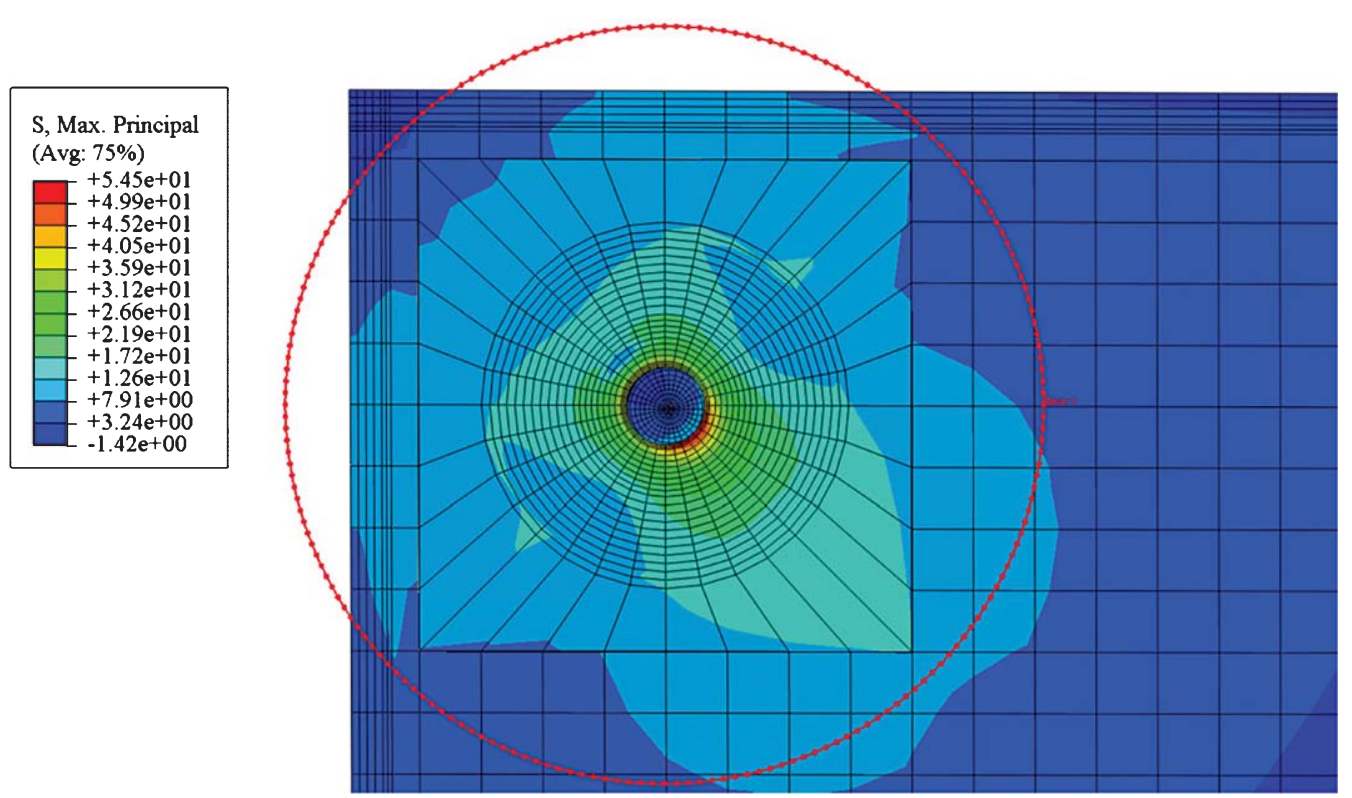

Fig. 37. Location of the stress peak in single glazing with indication of the local area $(r=72.5 \mathrm{~mm})$.

\subsection{Location of stress peak in single and insulation glass}

The point-fitted single glazing has the same dimensions as the inner pane of the insulation glass unit (Section 7.2). A wind suction load of $p_{e, w}=-2.5 \mathrm{kN} / \mathrm{m}^{2}$ is applied.

In accordance to Beyer (2007), the stress peak always occurs at the rim of the borehole oriented towards the inner side of the glass pane (Fig. 37). 

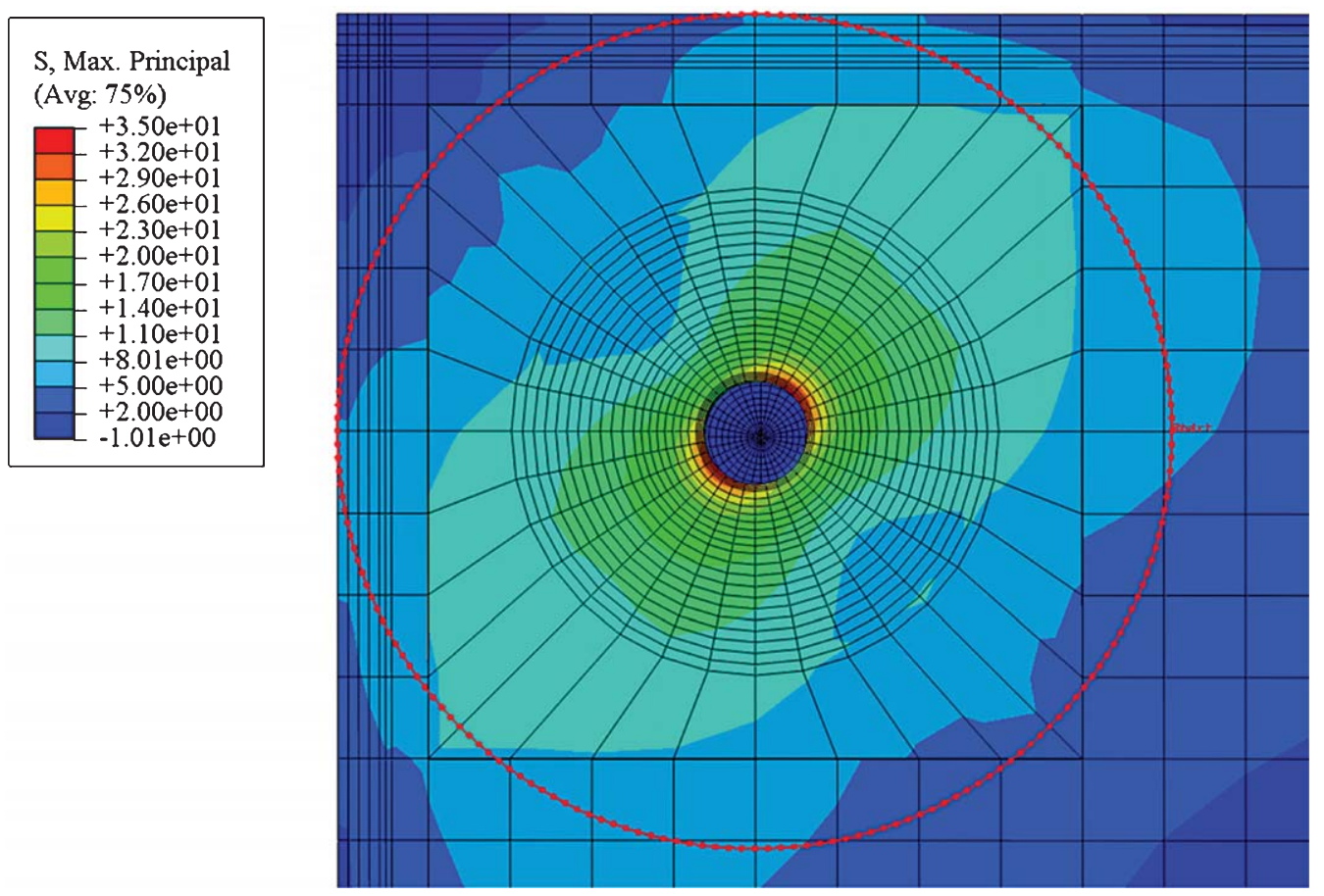

Fig. 38. Location of the stress peak in insulation glazing with indication of the local area $(r=60 \mathrm{~mm})$.

This is noticed for all edge distances and justifies the definition of a radius of $72.5 \mathrm{~mm}$ (Beyer, 2007) for the local area of single glazing: even if the local area overtops the edge of the plate, the global component is read on the opposite side.

In insulation glazing, the stress peak however occurs at the rim of the borehole oriented towards the free edge of the unit (Fig. 38).

In consequence, the overlapping of the local area has to be avoided and its size has to be reduced. Finally a radius of $60 \mathrm{~mm}$ is proposed for the local area of insulation glass units with the Fischer FZP-G-Z (Tibolt, Hechler, \& Odenbreit, 2013).

\section{Conclusion and outlook}

The impact of the European strategy 'EU2020' on the design of glass facades is illustrated. In addition to transparency, thermal insulation became another important requirement on facades. Point fitted insulation glass units with undercut anchors are revealed to comply best with the architectural demands on modern facades (Tibolt, 2015). They consist of the most promising compromise between high transparency and energy performance.

Four different design methods for point-fitted single glazing are highlighted. The SLG-method is identified to be the most appropriate concept for the design of point fitted glazing. Since an adequate design concept for undercut point fitted insulation glass does actually not exist, a design approach in 5 steps is proposed. It accounts for the load bearing mechanism of point-fitted insulation with undercut anchors. The approach is based on the SLG-method and requires its extension to insula- 
tion glass. For the extension, the size of the local area and the stress concentration factors need to be readopted, especially under consideration of the edge bond influence. Focus of this paper has been put on the investigation of the edge bond stiffness influence on the stress peak at the borehole and the local stress distribution. Moreover the size of the local area for point fitted IGU is defined.

First, experimental investigations in the FZP-G-Z in monolithic glass plates have been presented. From these tests the characteristic resistances and corresponding partial safety factors have been determined and compared to the values in Z-70.2-122 (2007). Good correspondence between the approval and the test results is noticed and the values in Z-70.2-122 (2007) are confirmed. Moreover, the global safety concept in Z-70.2-122 (2007) has been identified to be conservative compared to the partial safety concept in DIN EN (1990).

Secondly a numerical model of the FZP-G-Z has been introduced. The element and mesh quality of the glass pane, the contact definitions and the rotational stiffness of the point fitting have been verified by comparison to the results in (Beyer (2007)) and Z-70.2-122 (2007). Finally the overall FEmodel of the point fitting has been calibrated by checking the measured strains in the test against the numerically calculated strains. In this way, the FE-model could be validated.

Thirdly, the FE-model was implemented in a selected insulation glass geometry. A parametric study on the influence of the edge bond geometry and stiffness on the stress peak at the borehole has been conducted. A common dual-sealed edge seal configuration with four different dimensions has been chosen. Different silicone material laws for the secondary sealant and the spacer have been adopted for the study. Nearly no influence of the spacer stiffness and the primary PIB sealant on the stress peak and the stress distribution in the borehole area has been observed. The secondary silicone sealant has been revealed to have the biggest influence on the stress peak. The higher the stiffness of the sealant, the higher is the stress peak. The highest stress peak was observed for the hyperelastic material law of Dias (2013). Moreover, the influence of the sealant stiffness decreases with increasing edge distances of the point fitting. The reason is a change of the load bearing mechanism of the Fischer FZP-G-Z with increasing secondary sealant stiffness and edge distances of the point fitting.

The stress distribution among the path of the tensile stress peak has been determined, once with an exact 3D-model with solid elements and once with the 2D-model with shell elements for the glass panes, no borehole and the point fitting modelled with spring elements. At a distance of about $45 \mathrm{~mm}$ from the borehole centre, the stress distributions of both models are converting in good accordance to the Principle of Saint-Venant. The same observation has been done for the principal stress in the mid-span of the inner and outer glass panes. In consequence, the stress state in the global area of the glass plate can be determined with a 2D-FE-model and the SLG-method is principally extendable to point-fitted insulation glass.

Finally, an investigation of the stress peak location at the borehole in single and insulation glass has been done. In contrary to single glazing, the stress peaks in insulation glass also appears at the rim of the borehole oriented towards the free glass edge. Thus, to avoid the local area to overlap the glass edge, its size has been limited to the minimal edge distance of the point fitting, namely $r=60$ $\mathrm{mm}$.

In future research, the influence of the edge bond stiffness on the stress peak and the local stress distribution will be investigated for varying IGU dimensions to generalize the results of this paper. In addition, new stress concentration factors will be derived for point-fitted insulation glass units with undercut anchors (Tibolt, 2015). 


\section{Acknowledgments}

The authors wish to express their deep gratitude to ArcelorMittal for their financial support, Guardian Luxembourg and VitrumLux for their support with glass materials, Fischer for the provision of the FZP-G-Z point fittings and their insertion in the glass panes as well as their inspiring cooperation.

\section{References}

Beyer, J. (2007). Ein Beitrag zum Bemessungskonzept für punktgestützte Glastafeln, (Doctoral dissertation). Technische Universität Darmstadt, Germany.

Beyer, J. (2009). Glass design using the SLG-method. Retrieved from http://www.glassfiles.com/articles/glass-design-using-slg-method

Bostik (2008). V-70: High strength structural glazing silicone adhesive sealant (Technical data sheet). Retrieved from http://www.hoganswholesale.com.au/files/Bostik-V70-TDS.pdf

Brendler, S., \& Schneider, S. (2004). Bemessung von punktgelagerten Verglasungen mit verifizierten Finite-Elemente-Modellen, DIBtMitteilungen, 35(6), 196-203.

Bundesministerium für Umwelt, Naturschutz und Reaktorsicherheit (BMU) (2009). EnEV 2009: Verordnung über energiesparenden Wärmeschutz und energiesparende Anlagentechnik bei Gebäuden. Retrieved from http://www.enevonline.org/enev_2009_volltext/index.htm

Deutsches Institut für Normung (2002). DIN EN 1990: Grundlagen der Tragwerksplanung (DIN EN 1990). Berlin, Germany: DIBT.

Deutsches Instituts für Bautechnik (DIBT) (2004). Punktgehaltene Verglasungen mit Glasslinie-Tellerhaltern: Allgemeine bauaufsichtliche Zulassung (Z-70.2-99). Berlin, Germany: DIBT.

Deutsches Instituts für Bautechnik (DIBT) (2007). Punktgehaltene Verglasung mit fischer Zykon Punkthaltern (FZP-G-Z): Allgemeine bauaufsichtliche Zulassung (Z-70.2-122). Berlin, Germany: DIBT.

Deutsches Institut für Normung (2010). DIN 18008-1: Glas im Bauwesen - Bemessungs- und Konstruktionsregeln, Teil 1: Begriffe und allgemeine Grundlagen (DIN 18008-1). Berlin, Germany: Beuth Verlag.

Deutsches Institut für Normung (2010). DIN EN 1991-1-3: Einwirkung auf Tragwerke, Teil1-3: Allgemeine Einwirkungen, Schneelasten (DIN EN 1991-1-3). Berlin, Germany: Beuth Verlag.

Deutsches Institut für Normung (2010). DIN EN 1991-1-4: Einwirkung auf Tragwerke, Teil1-4: Allgemeine Einwirkungen, Windlasten (DIN EN 1991-1-4). Berlin, Germany: Beuth Verlag.

Deutsches Institut für Normung (2013). DIN 18008-3: Glas im Bauwesen - Bemessungs- und Konstruktionsregeln, Teil 3: Punktförmig gelagerte Verglasungen (DIN 18008-3). Berlin, Germany: Beuth Verlag.

Dias, V. (2013). Development of adhesives constitutive material laws for the assessment of bonded steel to glass partial composite beams (Doctoral dissertation). University of Luxembourg, Luxembourg.

Dow Corning (2004). Qualitätshandbuch für Isolierglas - Leitfaden für die Verwendung von Silicondichtstoffen bei der Isolierglasfertigung. Wiesbaden, Germany: Dow Corning GmbH.

European Commission (2007). Accelerating the Development of the Sustainable Construction Market in Europe: Report of the task-force on Sustainable construction (COM (2007) 860 final). Retrieved from http://ec.europa.eu/enterprise/policies/innovation/policy/lead-marketinitiative/files/construction_taskforce_report_en.pdf

European Organisation for Technical Approvals (EOTA) (2012). ETAG 002: Structural sealant glazing kits (SSGK) (ETAG 002). Retrieved from http://www.sgpstandard.cz/editor/files/stav_vyr/dok_es/eta/etag/002_1_en.pdf

Hechler, O., Dias, V., Odenbreit, C., Tibolt, M., \& Zilian, A. (2012). Design concept for point fitting of insulation glass units. In Proceedings of VI International Congress on Architectural Envelopes (ICAE). San Sebastian, Spain.

Kasper, R. (2006). Berechnungskonzept für die Bemessung von punktförmig gelagerten Glasscheiben. Stahlbau, 75(6), 454-461.

Külmeyer, M. (2001). Statistische Auswertungsmethoden für Ingenieure. Berlin, Germany: Springer Verlag.

O'Hara, G. P. (1983). Mechanical Properties of Silicone Rubber in a Closed Volume (Report ARLCB-TR-83045, SBI-AD-E440224). Large Caliber Weapon Systems Laboratory, Army Armament Research and Development Center.

Schäfer, M. (2002). Darstellung hochmolekularer und verzweigter Polyisobutene durch Einsatz von Makroinitiatoren, cyclischen Dienen und Initiatormonomeren. (Doctoral dissertation). Technische Universität München, Germany.

Schneider, J. (2001). Festigkeit und Bemessung punktgelagerter Gläser und stoßbeanspruchter Gläser. (Doctoral dissertation). Technsiche Universität Darmstadt, Germany.

Schneider J., Hof P., \& Block, C. (2002). Fastening of Glass Panes with Undercut Anchors. Numerical tempering simulation, experiments, load-bearing-capacity. Proceedings of the 2nd International Colloquium on Modelling of Glass Forming and Tempering (M.G.F.T) (pp. 247-254). University of Valencienne2, France. 
Siebert, B. (2006). Anforderungen für ein Berechnungskonzept für die Bemessung punktgelagerter Verglasungen. Stahlbau, 75(8), 652-657. Sika (2012). Sikasil ${ }^{\circledR}$ SG-20: High strength structural silicone sealant (Product data sheet). Retrieved from http://SIL\%20SG-20\%20$\% 20642$.pdf

Tibolt, M., Hechler, O., \& Odenbreit, C. (2013). Numerical investigation of insulation glass units with undercut point fittings. In J. Belis, C. Louter \& D. Mocibob (Eds.), COST Action TU0905: Mid-Term Conference on Structural Glass (pp. 437-445). Poreč, Croatia: CRC Press.

Tibolt, M., Hechler, O., \& Odenbreit, C. (2014). Analytical extension of a climate load model for undercut point fitted IGU. In C. Louter, F. Bos \& J. Belis (Eds.), Challenging Glass 4 \& COST Action TU0905 Final Conference (pp. 199-208). Lausanne, Switzerland: IOS Press.

Tibolt, M. (2015). Investigations in discrete connections between insulating glass and steel for energy efficient and transparent building envelopes (Doctoral dissertation). University of Luxembourg, Luxembourg. To be published.

Van den Bergh, S., Hart, R., Jelle, P., \& Gustavsen, A. (2013). Window spacers and edge seals in insulating glass units: A state-of-the-art review and future perspectives. Energy and Buildings, 58, 263-280.

Wurm, J. (2007). Glass structures: Design and construction of self-supporting skins. Basel, Switzerland: Birkhäuser Verlag.

Young, W. C. (1989). Roark's Formulars for Stress and Strain, (6th ed.). Singapore, Singapore: McGraw Hill. 